\title{
Mixing state of refractory black carbon in fog and haze at rural sites in winter on the North China Plain
}

\author{
Yuting Zhang ${ }^{1,2}$, Hang Liu ${ }^{1,2}$, Shandong Lei ${ }^{1,2}$, Wanyun $\mathrm{Xu}^{3}$, Yu Tian ${ }^{1,2}$, Weijie Yao ${ }^{1,2}$, Xiaoyong Liu ${ }^{1,2,5}$, Qi Liao ${ }^{1,2}$, \\ Jie Li ${ }^{1}$, Chun Chen ${ }^{1,2}$, Yele Sun ${ }^{1,2,5}$, Pingqing Fu ${ }^{4}$, Jinyuan Xin ${ }^{1,2,6}$, Junji Cao ${ }^{7}$, Xiaole Pan ${ }^{1}$, and Zifa Wang \\ ${ }^{1}$ State Key Laboratory of Atmospheric Boundary Layer Physics and Atmospheric Chemistry, \\ Institute of Atmospheric Physics, Chinese Academy of Sciences, Beijing 100029, China \\ ${ }^{2}$ College of Earth and Planetary Sciences, University of Chinese Academy of Sciences, Beijing 100049, China \\ ${ }^{3}$ State Key Laboratory of Severe Weather \& Key Laboratory for Atmospheric Chemistry, Institute of Atmospheric \\ Composition, Chinese Academy of Meteorological Sciences, Beijing 100081, China \\ ${ }^{4}$ Institute of Surface-Earth System Science, Tianjin University, Tianjin 300072, China \\ ${ }^{5}$ Center for Excellence in Regional Atmospheric Environment, Institute of Urban Environment, \\ Chinese Academy of Sciences, Xiamen 361021, China \\ ${ }^{6}$ Collaborative Innovation Center on Forecast and Evaluation of Meteorological Disasters, \\ Nanjing University of Information Science and Technology, Nanjing 210044, China \\ ${ }^{7}$ Institute of Atmospheric Physics, Chinese Academy of Sciences, Beijing, China
}

Correspondence: Xiaole Pan (panxiaole@mail.iap.ac.cn)

Received: 17 May 2021 - Discussion started: 6 August 2021

Revised: 23 October 2021 - Accepted: 5 November 2021 - Published: 3 December 2021

\begin{abstract}
The variability of the mixing state of refractory black carbon aerosol $(r \mathrm{BC})$ and the corresponding complicated light absorption capacity imposes great uncertainty for its climate forcing assessment. In this study, field observations using a single-particle soot photometer (SP2) were conducted to investigate the mixing state of $r \mathrm{BC}$ under different meteorological conditions at a rural site on the North China Plain. The results showed that the hourly mass concentration of $r \mathrm{BC}$ during the observation periods was $2.6 \pm 1.5 \mu \mathrm{g} \mathrm{m} \mathrm{m}^{-3}$ on average, with a moderate increase $(3.1 \pm 0.9)$ during fog episodes. The mass-equivalent size distribution of $r \mathrm{BC}$ exhibited an approximately lognormal distribution with a mass median diameter (MMD) of $213 \mathrm{~nm}$. We found that the count median diameter (CMD) of $r \mathrm{BC}$ particles during snowfall episodes was larger than that before snowfall, and the number of $r \mathrm{BC}$ particles with $D_{\mathrm{c}}<121 \mathrm{~nm}$ were reduced by $28.4 \%$ after snow. This may indicate that $r \mathrm{BC}$-containing particles with small core sizes $\left(D_{\mathrm{c}}\right)$ were much more effectively removed by snow with light snow intensity $\left(0.23 \mathrm{~mm} \mathrm{~h}^{-1}\right)$. Based on the Mie scattering theory simulation, the relative and absolute coating thicknesses of $r \mathrm{BC}$-containing particles were estimated to be $\sim 1.6$ and $\sim 52 \mathrm{~nm}$ for the $r \mathrm{BC}$ core
\end{abstract}

with a mass-equivalent diameter $\left(D_{\mathrm{c}}\right)$ of 170 to $190 \mathrm{~nm}$, respectively, which indicates that most of the $r \mathrm{BC}$-containing particles were thinly coated. Furthermore, a moderate light absorption enhancement $\left(E_{\mathrm{abs}}=1.3\right)$ and relatively low absorption cross section $\left(\mathrm{MAC}=5.5 \mathrm{~m}^{2} \mathrm{~g}^{-1}\right.$ ) at $880 \mathrm{~nm}$ were observed at the Gucheng (GC) site in winter compared with other typical rural sites.

The relationship between the microphysical properties of $r \mathrm{BC}$ and meteorological conditions was also studied. Relatively warm and high-RH environments ( $\mathrm{RH}>50 \%$, $-4{ }^{\circ} \mathrm{C}<T<4{ }^{\circ} \mathrm{C}$ ) were more favorable to $r \mathrm{BC}$ aging than dry and cold environments ( $\left.\mathrm{RH}<60 \%, T<-8^{\circ} \mathrm{C}\right)$. And the increase in ambient $\mathrm{RH}$ at the same temperature favors $r \mathrm{BC}$ aging. An increasing mass fraction of secondary inorganic aerosols (SIAs; especially sulfate and nitrate) and a decreasing mass fraction of organic aerosols in the environment support the formation of thick coatings by $r \mathrm{BC}$. The RH dependence of absorption enhancement $\left(E_{\text {abs }}\right)$ was likely caused by the relative coating thickness (RCT) as supported by the gradual increase in the mass concentration and mass fraction of secondary components as a function of RH in the ambient air. The mass fractions of aqueous-phase formation 
of secondary components had a limited effect on $E_{\text {abs }}$ under a high-RH environment. The measured $r \mathrm{BC}$ concentrations and the mixing state of $r \mathrm{BC}$ in different meteorological environments will be useful for evaluating the radiative forcing of $r \mathrm{BC}$ in regional climate models.

\section{Introduction}

As an absorbing aerosol produced by incomplete combustion, black carbon plays a leading role in the absorption of shortwave solar radiation and changes atmospheric thermodynamics through the heating effect. Black carbon is an important factor leading to highly uncertain climate warming (Bond et al., 2013; Moffet and Prather, 2009). Black carbon aerosols enhance haze pollution by absorbing solar radiation to change the meteorological characteristics of the planetary boundary layer (PBL) (Ding et al., 2016). Freshly discharged black carbon is hydrophobic and becomes hydrophilic when mixed with hydrophilic material during aging, acting as cloud condensation nuclei $(\mathrm{CCN})$ (Sarangi et al., 2019; Twomey, 1974) and increasing the cloud drop number concentration (Cherian et al., 2017). Wet removal is a key factor in determining the lifetime of black carbon aerosols in the atmosphere, which determines their vertical and horizontal distribution, local and regional diffusion, and direct, semidirect, and indirect radiative forcing effects (Liu et al., 2013).

The burning of fossil fuels such as coal and oil and the burning of biomass in agricultural production caused by human activities are the main factors leading to the increasing black carbon emissions. Using a transmission electron microscope fitted with an environmental cell (ETEM), we observed that fresh black carbon presents a loose and porous chain structure, and then in the atmosphere through condensation, coagulation, heterogeneous oxidation condensation, or heterogeneous chemical reaction, refractory black carbon aerosol $(r \mathrm{BC})$ is coated by soluble material, and the coating gradually becomes thicker with increasing $\mathrm{RH}$ (He et al., 2015; Freney et al., 2010). The mixing state determines the morphology and optical properties of black carbon, affects its wet removal efficiency, and thus affects the atmospheric lifetime (Yu et al., 2020). The extent of $r$ BC coating has been considered to be an important factor in evaluating aerosol radiative capacity (Oshima et al., 2009). It has been shown that the mixing of $\mathrm{BC}$ and other non-BC materials can enhance radiation absorption, which is interpreted as exhibiting a "lensing effect," with the magnitude strongly dependent on the $r$ BC coating amount (Cappa et al., 2012; Liu et al., 2015; Moffet and Prather, 2009). Generally, $r$ BC-containing particles with thicker coatings have higher hygroscopic properties and can act as $\mathrm{CCN}$ under severe pollution conditions (Ding et al., 2019; Schwarz et al., 2008). Under high-pollution and RH conditions, the absorption efficiency of black carbon was significantly increased. Reducing the emission of BC and related secondary coating precursors is an effective way to alleviate the direct radiation effect of $\mathrm{BC}$ in urban environments. However, the change in the mixing state of black carbon aerosols and their driving factors are not clear under highpollution and RH conditions.

The North China Plain is one of the BC hotspots with intensive anthropogenic emissions (Cao et al., 2006; Yang et al., 2016). Recently, the spatiotemporal distribution and optical properties of $r \mathrm{BC}$ and its influence on climate and the environment have been reported (D. Zhao et al., 2020; Ding et al., 2019; Liu et al., 2020b). However, observations of the mixing state of black carbon under different meteorological conditions are still insufficient. The single-particle soot photometer (SP2) with high resolution and high precision has significant advantages in estimating the mixing state of black carbon. During recent years, an increasing number of observations have used SP2 instruments to observe the mixing state of black carbon in China (Wang et al., 2014; Gong et al., 2016; Liu et al., 2020b; Pan et al., 2017). Most studies have focused on the mixing state of $\mathrm{BC}$ on severe haze days because of the presence of large amounts of particulate matter and gaseous precursors in the atmosphere. Studies have focused on the chemical mechanisms such as condensation, coagulation, and heterogeneous oxidation for coating formation (He et al., 2015; Bond et al., 2013), while the connection between meteorological factors and coatings is relatively rare. Previous studies have shown that wind speed and variation in the planetary boundary layer (PBL) can influence the concentration of BC (Talukdar et al., 2019) and that relative humidity $(\mathrm{RH})$ affects the morphology and hygroscopic growth of $r$ BC-containing particles (Laborde et al., 2013; Freney et al., 2010). Meteorological fields may have an impact on the mixing state of $r \mathrm{BC}$.

In this study, SP2 was deployed at a moderately polluted rural site on the North China Plain in winter to characterize the size distribution and mixing state of $r \mathrm{BC}$. This work is unique due to the largely different meteorological conditions during the campaign. The differences in $r \mathrm{BC}$ particle size under different meteorological conditions are illustrated, and the main factors influencing the $r \mathrm{BC}$ mixing state are discussed. The results of this paper were exhibited in the following sequence: (1) the size distribution of $r \mathrm{BC}$ in different campaigns, (2) the relative and absolute coating thickness and optical properties of $r \mathrm{BC}$-containing particles and their influencing factors, and (3) the relationship of the aging process of $r \mathrm{BC}$ with meteorological conditions such as $\mathrm{RH}$, temperature, and pollution conditions. 


\section{Observations}

\subsection{Site description and measurements}

The observation of refractory $\mathrm{BC}(r \mathrm{BC})$ particles was performed from 7 December 2019 to 1 January 2020, in an airconditioned container located in farmland of the Gucheng (GC; latitude: $39^{\circ} 7.8^{\prime} \mathrm{N}$; longitude: $115^{\circ} 48^{\prime} \mathrm{E}$ ) site in Dingxing County, Hebei Province, China, which is part of the China Atmosphere Watch Network (CAWNET), operated by the Chinese Meteorological Administration. As shown in Fig. S1a in the Supplement, the observation station is located $\sim 120 \mathrm{~km}$ southwest of Beijing, adjacent to National Highway 107 (G107) and the Beijing-Hong KongMacau Expressway (G4). This result indicates that the sampling site was affected by traffic emissions sources, which is a feature compared to other typical rural sites mainly affected by biomass burning sources at home and abroad. A single-particle soot photometer (SP2, Droplet Measurement Technologies Inc. USA) was used to measure $r \mathrm{BC}$. A high-resolution time-of-flight aerosol mass spectrometer (HR-AMS, Aerodyne Research Inc., USA) was used to measure the non-refractory submicron (NR-PM1) aerosol species (organics, sulfate, nitrate, ammonium, and chloride). More details on this instrument can be found in previous studies (Jimenez, 2003; Kumar et al., 2016). Ambient relative humidity varied from $9 \%$ to $100 \%$ during the observation period, with an average relative humidity of $66 \%$.

\subsection{SP2 data analysis}

\subsubsection{Instrument and calibration}

The measurement of the size distribution and mixing state of individual $r \mathrm{BC}$-containing particles in $\mathrm{GC}$ was characterized using an SP2. The aerosol sampling inlet was placed on a lift tower $3.5 \mathrm{~m}$ above the ground, and ambient air entered the container through a $1 / 2$ in. soft tube. The SP2 was operated at a sampling flow rate of $100 \mathrm{~cm}^{3} \mathrm{~min}^{-1}$. There was a continuous-wave intracavity Nd: YAG laser beam $(1064 \mathrm{~nm}$, TEM00 mode) in the SP2 measurement chamber. The SP2 used particle identification by laser-induced incandescence technology to observe and identify $r \mathrm{BC}$ (Stephens et al., 2003; Schwarz et al., 2006b). All particles scatter light, but only when they contain highly absorbent and refractory components, such as $r \mathrm{BC}$, do they absorb the laser radiation and are heated to their boiling point temperature before emitting blackbody radiation (Liu et al., 2010; Moteki and Kondo, 2007). When particles cross the laser, particles' composition and size can be determined by detecting the incandescence signal when particles evaporated and the elastic scattering signal of particles. The ratio of the signals observed at the detectors for the narrowband, and broadband is used for estimating the color temperature of thermal radiation from $r \mathrm{BC}$ containing particles and, thereby, constrains particle compo- sition (Schwarz et al., 2006a). If only the scattering signal was detected, it was proven that the particles do not contain $r \mathrm{BC}$ and are purely scattering particles (non- $r \mathrm{BC}$ ). If both the scattering signal and the incandescence signal were recorded, it was an $r \mathrm{BC}$-containing particle. In general, $r \mathrm{BC}$ containing particles need more time to evaporate the nonrefractory matter before reaching their boiling point temperature. Therefore, there was a lag time $(\Delta t)$ for the peak of the incandescence signal and the scattering signal, which can be used to qualitatively study the mixing state of $r \mathrm{BC}$ containing particles. For SP2, the detectable size range of the scattering signal was $200-400 \mathrm{~nm}$ diameter. Assuming a black carbon density of $1.8 \mathrm{~g} \mathrm{~cm}^{-3}$ and an ideally spherical structure, the mass equivalent diameter of black carbon detected by the incandescence signal is $70-500 \mathrm{~nm}$.

Prior to the observation field campaign, the scattering and incandescence signals of SP2 were calibrated in the laboratory. Aquadag aerosols (lot no. 9627, Acheson Inc., USA) were used to calibrate the incandescence signal. We used an atomizer (model 3072, TSI Inc, USA) and a diffusion dryer to prepare monodispersed Aquadag aerosols, which were selected according to mobility diameter using a differential mobility analyzer (DMA; Model 3081, TSI Inc., 150 USA). The calibration coefficient values for broadband high gain (BBHG) and broadband low gain (BBLG) of incandescence signals are shown in Fig. S2. We corrected the incandescence signal for ambient $r \mathrm{BC}$ with a scaling factor of 0.75 because the SP2 is more sensitive to Aquadag than diesel emission $r \mathrm{BC}$ in the same mass range (Laborde et al., 2012; Baumgardner et al., 2012). The scattering signal was calibrated using polystyrene latex spheres (PSL; Nanosphere Size Standards, Duke Scientific Corp., USA). In addition to the above instruments, a condensation particle counter (CPC, model 3775, TSI Inc., USA) was adopted to measure the number concentration of particles to compare with the SP2.

\subsubsection{Shell-core calculation}

A single-particle $r \mathrm{BC}$ mass was obtained by the incandescence signal. We usually refer to the mass equivalent diameter converted by the $r \mathrm{BC}$ mass $\left(\rho=1.8 \mathrm{~g} \mathrm{~cm}^{-3}\right.$ for ambient $\mathrm{BC})$ as the $r \mathrm{BC}$ core diameter $\left(D_{\mathrm{c}}\right)$, which is the diameter of a void-free, spherical structure, as expressed in Eq. (1):

$D_{\mathrm{c}}=\sqrt[3]{\frac{6 \times M_{r \mathrm{BC}}}{\pi \times \rho_{r} \mathrm{BC}}}$.

Information about the scattering signal of $r \mathrm{BC}$-containing particles detected by the SP2 is distorted because when individual $r \mathrm{BC}$ particles passed through the laser beam, they absorb the laser energy and are heated up to $\sim 4000 \mathrm{~K}$, resulting in mass loss of a single $r \mathrm{BC}$ particle directly. Thus, the methodology of leading-edge-only (LEO) fitting is adopted to characterize the original scattering properties and coating thickness of $r \mathrm{BC}$-containing particles. The scattering signal of purely scattering particles is Gaussian, as detected by 
the SP2. In this method, the Gaussian fitting of the original scattering signal is reconstructed from the leading edge of the scattering signal (before the volatilization of particles) of $r$ BC-containing particles (Gao et al., 2007). In this study, $r \mathrm{BC}$-containing particles are assumed to be shell-core structures. The optical diameter of $r \mathrm{BC}$-containing particles or coated diameter $\left(D_{\mathrm{p}}\right)$ is calculated by Mie table calculations. Using a core refractive index $n_{\mathrm{c}}=2.26+1.26 i$ and a coating refractive index $n_{\mathrm{s}}=1.48+0 i$, we input the LEO fitted scattering signal and $r \mathrm{BC}$ core size into Mie calculations (Taylor et al., 2015). Further, the relative coating thickness (RCT) and absolute coating thickness (ACT) of an $r$ BC-containing particle, calculated as $D_{\mathrm{p}} / D_{\mathrm{c}}$ and $\left(D_{\mathrm{p}}-D_{\mathrm{c}}\right) / 2$, respectively.

\subsubsection{Calculation of $r \mathrm{BC}$ optical properties}

The ensemble effect of light absorption by $r$ BC-containing particles is calculated at $880 \mathrm{~nm}$ because the optical properties of $r \mathrm{BC}$-containing particles at this wavelength are hardly affected by brown carbon $(\mathrm{BrC})$. Based on the size information of $r \mathrm{BC}$-containing particles (i.e., $D_{\mathrm{c}}$ and $D_{\mathrm{p}}$ ) obtained by SP2 observation, optical parameters such as the mass absorption cross section (MAC), absorption enhancement $\left(E_{\mathrm{abs}}\right)$, and absorption coefficient $\left(\sigma_{\mathrm{abs}}\right)$ of $r \mathrm{BC}$-containing particles can be obtained based on Mie scattering theory. The refractive index of the $r \mathrm{BC}$ core was $2.26+1.26 i$, and the refractive index of $1.48+0 i$ was used for coatings in the Mie calculation assuming $r \mathrm{BC}$-containing particles constitute a core-shell model. In addition to the absorption of light by the $r \mathrm{BC}$ core, coating materials on the surface of $r \mathrm{BC}$ can attract more light to the $r \mathrm{BC}$ core, which is called the lensing effect, enhancing the light absorption of $r \mathrm{BC}$. The $E_{\mathrm{abs}}$ can be used to quantify the theoretical light absorption capability of $\mathrm{BC}$-containing particles. $E_{\mathrm{abs}}$ is determined by the ratio of the absorption cross section of the whole $r \mathrm{BC}$-containing particle $\left(C_{\mathrm{abs}, \mathrm{s}}\right)$ to the absorption cross section of the bare $r$ BC core $\left(C_{\text {abs,c }}\right)$, as shown in Eq. (2):

$E_{\mathrm{abs}}=\frac{C_{\mathrm{abs}, \mathrm{s}}}{C_{\mathrm{abs}, \mathrm{c}}}$.

MAC reflects the optical absorption characteristics of $r \mathrm{BC}$ containing particles in unit mass concentration. The larger the value is, the stronger the radiation absorption capacity of $r \mathrm{BC}$-containing particles is. The mass absorption cross section $\left(\mathrm{MAC}_{i}\right)$ of a single $r \mathrm{BC}$-containing particle is defined as the absorption cross section of the whole $r \mathrm{BC}$-containing particle $\left(C_{\mathrm{abs}, \mathrm{s}}\right)$ per unit $r \mathrm{BC}$ mass $\left(m_{r \mathrm{BC}, i}\right)$, as expressed in the following equation:

$\mathrm{MAC}_{i}=\frac{C_{\mathrm{abs}, \mathrm{s}}}{m_{r \mathrm{BC}, i}}$.

The MAC in bulk for a given period is calculated as
$\mathrm{MAC}=\frac{\sum_{i} \mathrm{MAC}_{i} \times m_{r \mathrm{BC}, i}}{\sum_{i} m_{r \mathrm{BC}, i}}$.

The $\sigma_{\text {abs }}$ of $r \mathrm{BC}$-containing particles is calculated based on the MAC and the mass concentration $\left(C_{r \mathrm{BC}}\right)$ measured by the SP2, as shown in Eq. (4):

$\sigma_{\mathrm{abs}, \text { calculated }}=\mathrm{MAC} \times C_{r \mathrm{BC}}$.

Previous studies have shown that the light absorption of $r \mathrm{BC}$ containing particles is related to their morphology (Liu et al., 2017, 2020b). Simple assumptions of a core-shell structure and the ideal spherical shape of $r \mathrm{BC}$ particles, used in Mie theory to calculate optical properties, cause uncertainty due to the lack of observation of optical size information and morphology.

\subsection{Dispersion and trajectory analysis}

The HYSPLIT (Hybrid Single-Particle Lagrangian Integrated Trajectory) model developed by NCEP (National Center for Environmental Prediction) and NCAR (National Center for Atmospheric Research) was widely used to simulate the air footprint area for dispersion and trajectory analysis, which was based on the Lagrangian transport model (https://ready.arl.noaa.gov/HYSPLIT_traj.php, last access: 28 February 2020) (Cohen et al., 2015; Fan et al., 2021b, a). The potential uncertainty of the HYSPLIT model is related to the meteorological assimilation datasets that drive the model simulation ( $\mathrm{Su}$ et al., 2015). In this study, the HYSPLIT model was used to investigate the source of air mass on the North China Plain. The dataset provided for HYSPLIT is the global reanalysis data in GDAS format (ftp://arlftp. arlhq.noaa.gov/pub/archives/gdas1, last access: 26 February 2020). It produces meteorological data four times a day, namely, at 00:00, 06:00, 12:00, and 18:00 UTC, and the horizontal resolution is $2.5^{\circ} \times 2.5^{\circ}$. The vertical direction has 17 levels, ranging from the ground surface to $10 \mathrm{hPa}$. Meteorological parameters including wind, temperature, humidity, potential height, and ground precipitation are also provided. During the simulation, the trajectory ensemble option starts multiple trajectories from the first selected starting location. Each member of the trajectory ensemble is calculated by offsetting the meteorological data by a fixed grid factor (one meteorological grid point in the horizontal direction and $0.01 \sigma$ units in the vertical direction). Air samples were released at 150 ma.g.l. from the GC site, and the simulation time of the backward trajectory was $5 \mathrm{~d}$. 


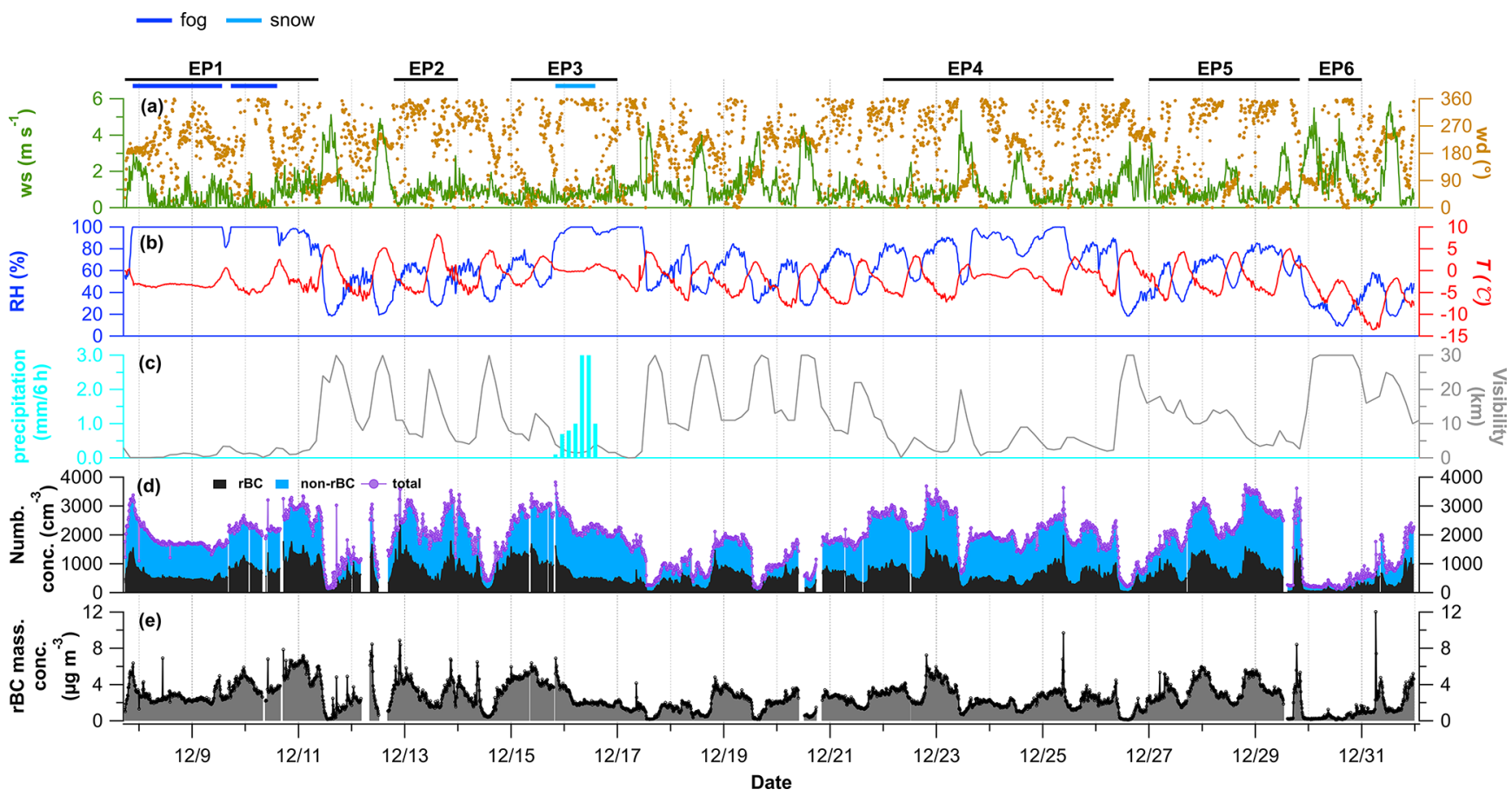

Figure 1. Time series of (a) wind speed (WS) and wind direction (WD), (b) relative humidity (RH) and ambient temperature (T), (c) precipitation and visibility, (d) number concentration of $r$ BC-containing particles, purely scattering particles and total particles measured by the SP2 in GC, and (e) $r$ BC mass loading.

\section{Results and discussion}

\subsection{Overview of the field observation}

\subsubsection{Meteorology}

The field campaign was performed from 8 to 31 December 2019. During the observation period, the site was affected by the winter monsoon with a prevailing northwesterly wind (Fig. S1b). The meteorological conditions and the concentration of aerosol particles during the sampling period are shown in Fig. 1. The average $( \pm 1 \sigma)$ wind speed was 1.2 $( \pm 1) \mathrm{m} \mathrm{s}^{-1}$, with the highest value up to $5.9 \mathrm{~m} \mathrm{~s}^{-1}$. According to the wind rose diagram, the northwest wind and the southwest wind prevailed during the observation, and the wind speed reached a maximum in the southwest direction during the whole sampling period according to the wind rose diagram (Fig. S1c). The relative humidity $(\mathrm{RH})$ during the entire period was relatively high, with an average $( \pm 1 \sigma)$ of $66( \pm 25) \%$. There were fog events and snowfall during the observation period. The period when the RH reached $100 \%$ between 7 and 11 December was defined as the fog event, and the visibility was almost $0 \mathrm{~km}$ during this period. Snowfall occurred at 20:00 on 15 December and lasted until 14:00 on 16 December, with snow intensity of $1.37 \mathrm{~mm}^{6} \mathrm{~h}^{-1}$. It was of great significance to study the mixing state and removal of $r \mathrm{BC}$-containing particles during fog and snow events to improve the model's simulation.

\subsubsection{Mass concentration of $r \mathrm{BC}$}

As shown in Fig. 1, the number concentrations of $r \mathrm{BC}$ and purely scattering particles showed similar variation trends. The average $( \pm 1 \sigma)$ number concentrations of $r \mathrm{BC}$ and purely scattering particles were $650 \pm 368$ and $1184 \pm$ $560 \mathrm{~cm}^{-3}$, respectively. The mass concentration of $r \mathrm{BC}$ in the ambient environment was $2.6( \pm 1.5) \mu \mathrm{g} \mathrm{m}^{-3}$, which was much lower than the observations in the winter of 2016 and 2018 at the urban site in Beijing. Liu et al. (2019) reported that the mass concentration of $r \mathrm{BC}$ in winter 2016 in Beijing was $6.4 \mu \mathrm{g} \mathrm{m}^{-3}$. Due to the strict air pollution control on coal combustion and biomass burning (Ji et al., 2017), Xie et al. (2020) found a decrease in mass concentration $\left(3.2 \mu \mathrm{g} \mathrm{m}^{-3}\right)$ in winter 2018. A similar urban-high and rurallow pattern was also found in Shenzhen, and the average mass loading of $r \mathrm{BC}$ in rural areas $\left(2.6 \mu \mathrm{g} \mathrm{m}^{-3}\right)$ in fall was much lower than that in urban areas $\left(6 \mu \mathrm{g} \mathrm{m}^{-3}\right)$ (Huang et al., 2012). One possible explanation was that rural sites have lower traffic emissions than urban sites, open biomass burning has been strictly controlled in recent years, and the goal of changing fuel from coal to natural gas has been well implemented, at least in the North China Plain (Huang et al., 2006; Ji et al., 2017).

Based on the meteorological conditions and concentrations of the total particles, six observation periods were chosen, as denoted in Fig. 1a: EP1 (17:40 on 7 December-09:00 on 11 December), EP2 (19:00 on 12 December-00:00 on 

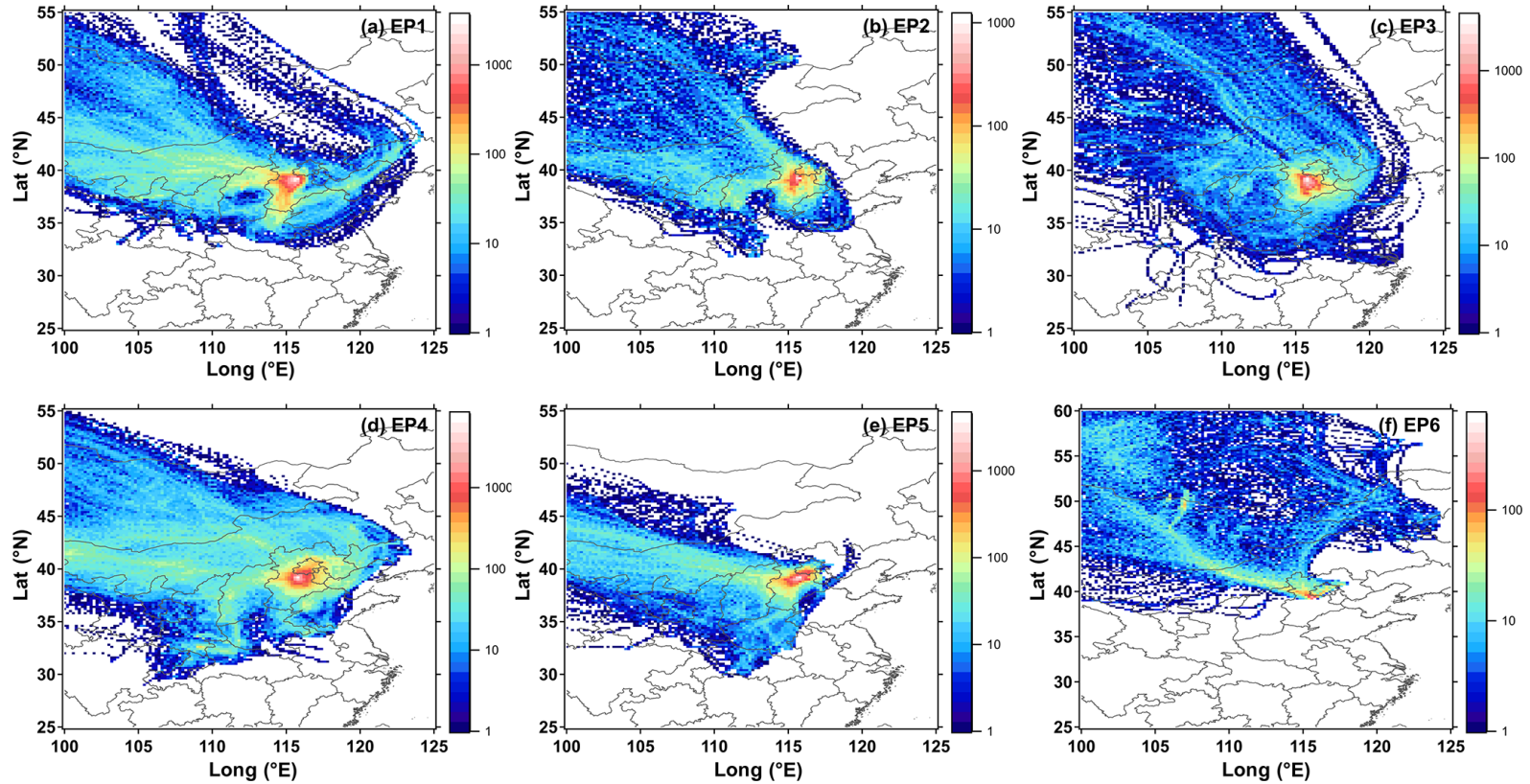

Figure 2. The backward trajectories from which the air mass over GC originated in varying periods.

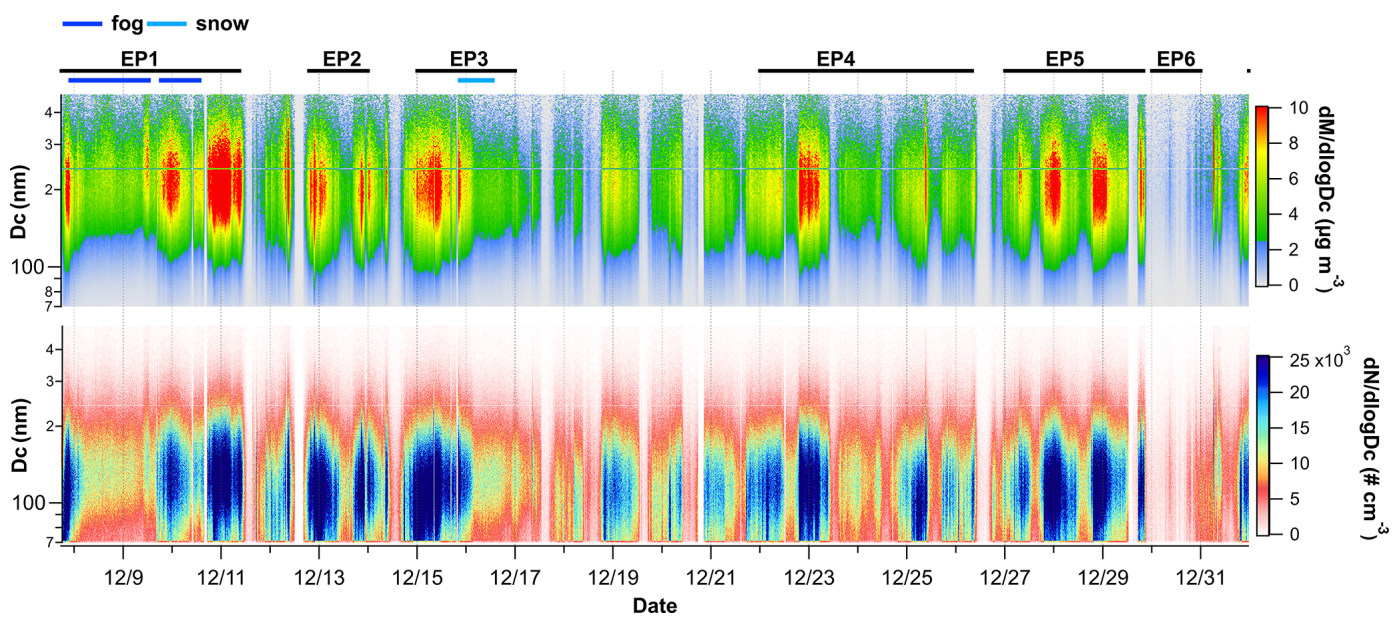

Figure 3. Time series of the mass size distribution and number size distribution of $r \mathrm{BC}$, as measured by the SP2.

14 December), EP3 (00:00 on 15 December-00:00 on 17 December), EP4 (00:00 on 21 December-00:00 on 26 December), EP5 (00:00 on 27 December-20:00 on 29 December) and EP6 (00:00 on 30 December-00:00 on 31 December). The periods with $\mathrm{RH}=100 \%$ during EP1 were defined as the fog period. The average $\mathrm{RH}$ was $96 \%$, and the average $r$ BC mass concentration was $3.6( \pm 1.4) \mu \mathrm{g} \mathrm{m}{ }^{-3}$ during EP1. During EP3, there was snow from 20:00 on 15 December to 14:00 on 16 December. Therefore, during EP3, the discussion is divided into before-snow, snow, and after-snow periods. In the other four periods, EP6 was the clean period with an average $r \mathrm{BC}$ mass concentration of $0.5( \pm 0.3) \mu \mathrm{g} \mathrm{m} \mathrm{m}^{-3}$, while EP2, EP4, and EP5 represented polluted periods with average $r \mathrm{BC}$ mass concentrations of $3.4( \pm 1.4), 1.2( \pm 1.2)$, and $3.4( \pm 1.3) \mu \mathrm{g} \mathrm{m}^{-3}$, respectively. The variables related to $r \mathrm{BC}$ and the meteorological conditions in the selected different periods are shown in Table S2. The HYSPLIT model was used to analyze the origin of the air masses during the different periods. As shown in Fig. 2a-f, the air masses over GC mainly came from the northwest and northeast directions during the clean period, and the wind speed was relatively high. During the pollution period, the air masses mainly came from the southwest and south directions and local areas. During the period of EP1 and EP3 with high RH, part of the air mass originated from the eastern Bohai Sea direction. 

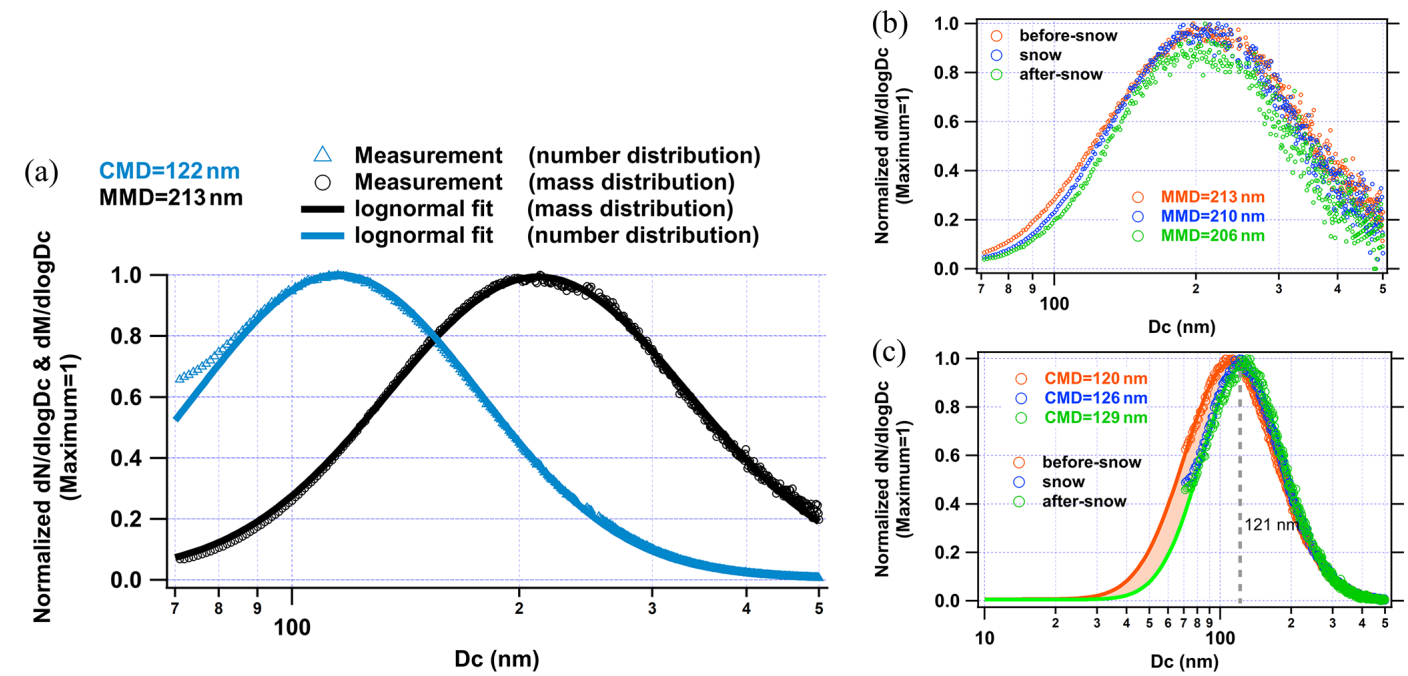

Figure 4. (a) Number and mass size distribution $\left(\mathrm{d} N / \mathrm{d} \log D_{\mathrm{c}}\right.$ and $\left.\mathrm{d} M / \mathrm{d} \log D_{\mathrm{c}}\right)$ of $r \mathrm{BC}$ core during the whole campaign. (b) Mass size distribution $\left(\mathrm{d} M / \mathrm{d} \log D_{\mathrm{c}}\right)$ during snowfall and (c) number size distribution $\left(\mathrm{d} N / \mathrm{d} \log D_{\mathrm{c}}\right)$ during snowfall. Note that the orange and green lines in (c) are the log-normal fit of number size distribution during the before-snow and after-snow periods, respectively. And the orange shaded areas denote the difference in area between the two log-normal fit curves at $D_{\mathrm{c}}$ less than $121 \mathrm{~nm}$.

\subsection{Size distribution of $r \mathrm{BC}$}

The time series of the mass size distribution and number size distribution of $r \mathrm{BC}$ during the whole experimental period was stable, with a modal size peaking at approximately 200 and $120 \mathrm{~nm}$, respectively (Fig. 3). The $r$ BC values measured by the SP2 at the GC site mainly were distributed in the range of $70-500 \mathrm{~nm}$, and the $r \mathrm{BC}$ mass and number values were concentrated at 100-400 and $<300 \mathrm{~nm}$, respectively. $\mathrm{d} M / \mathrm{d} \log D_{\mathrm{c}}$ and $\mathrm{d} N / \mathrm{d} \log D_{\mathrm{c}}$ showed an apparent diurnal trend. The peak period of diurnal variation was between 20:00 and 09:00 LST, while low diurnal variation occurred in the afternoon. This pattern was determined by the dual effects of diurnal variation in the boundary layer and local $r \mathrm{BC}$ emissions. To better study $\mathrm{d} M / \mathrm{d} \log D_{\mathrm{c}}$ and $\mathrm{d} N / \mathrm{d} \log D_{\mathrm{c}}$, the mass median diameter (MMD) and count median diameter (CMD) were used to represent the characteristics of $\mathrm{d} M / \mathrm{d} \log D_{\mathrm{c}}$ and $\mathrm{d} N / \mathrm{d} \log D_{\mathrm{c}}$ for detailed discussion.

Field measurements of the size of $r \mathrm{BC}$ around the world are summarized in Table 1. The size distribution as a function of $r \mathrm{BC}$ core mass equivalent diameter $\left(D_{\mathrm{c}}\right)$ measured by the SP2 is shown in Fig. 4. During the whole experiment, the mass size distribution followed the lognormal distribution and peaked at $213 \mathrm{~nm}$ (MMD) (Fig. 4a). As shown in Table 1, the MMD of $r \mathrm{BC}$ at the GC site in winter was slightly smaller than the value $(222 \mathrm{~nm})$ observed in rural areas in Shenzhen in November (Huang et al., 2012) and was consistent with the biomass burning emission observed in Texas (MMD $=210 \mathrm{~nm}$ ) (Schwarz et al., 2008). However, the $r \mathrm{BC}$ emitted by biomass burning in the laboratory was smaller $(189 \mathrm{~nm})$ (Pan et al., 2017). In addition, this mode was identical to the $r \mathrm{BC}$ mode observed in the aged continental air mass during a Paris study (Laborde et al., 2013). In comparison with most studies in urban areas, we found that the MMD of $r \mathrm{BC}$ in urban areas was smaller than that in our study (Huang et al., 2012; Gong et al., 2016; Liu et al., 2019, 2020b; Lan et al., 2013; Schwarz et al., 2008). Laborde et al. (2013) found that MMD was significantly related to the source of $r \mathrm{BC}$-containing particle emissions. Pan et al. (2017) showed that the MMD of $r \mathrm{BC}$ was also determined by combustion conditions and burning materials in a laboratory study. Many studies have indicated that the MMD of $r$ BC from traffic emissions was smaller than that from biomass burning, coal combustion, and aged air masses (Laborde et al., 2013; Schwarz et al., 2008). According to previous studies, MMD presented a trend of a small size in summer and a large size in winter, a small size in urban areas, and a large size in rural areas (Liu et al., 2019, 2020b; Huang et al., 2012; Kondo et al., 2016; Wu et al., 2021). The dense traffic arteries in urban areas and a large amount of traffic emissions may be the reason that MMD in urban areas is smaller than that in rural areas (Huang et al., 2006; Laborde et al., 2013; Schwarz et al., 2008). The different trends of MMD in seasons and spaces may be because $r \mathrm{BC}$ containing particles came from different emission sources. In addition, the MMD was higher in pollution events (i.e., EP1, EP2, EP3, and EP5). This was similar to the results of previous studies in which under the condition of a higher $r \mathrm{BC}$ mass concentration, the $r \mathrm{BC}$ core size usually increased (Liu et al., 2019). It could be that coagulation of $r \mathrm{BC}$ particles or regional transport causes changes in $r \mathrm{BC}$-containing particle sources at higher concentrations. 


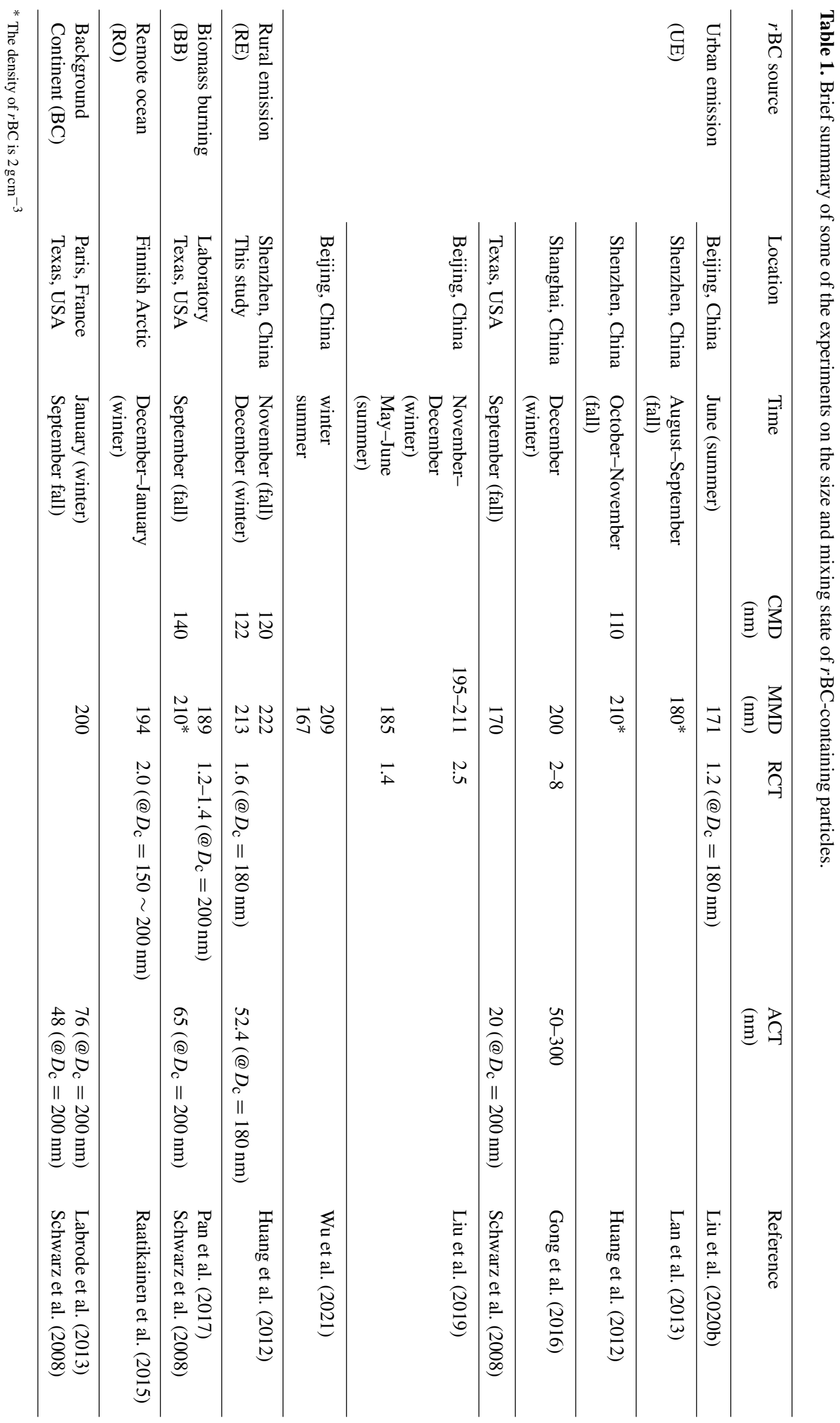




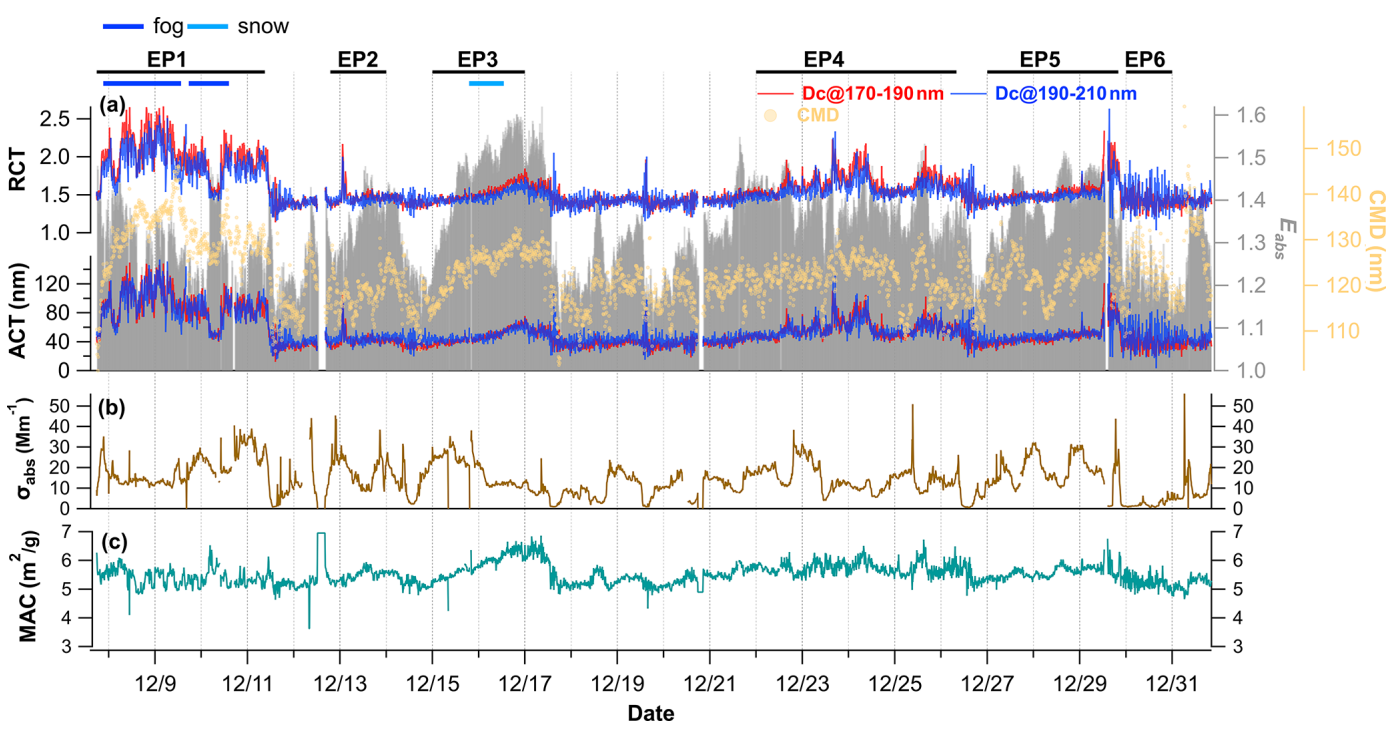

Figure 5. (a) Time series of the relative and absolute coating thicknesses of $r \mathrm{BC}$-containing particles within the $D_{\mathrm{c}}$ range of $170-190$ and $190-210 \mathrm{~nm}$. The gray bars denote the absorption enhancement $\left(E_{\mathrm{abs}}\right)$ of $r \mathrm{BC}$. The light yellow circles denote the size of the $r \mathrm{BC}$ core. Time series of the (b) absorption coefficient $\left(\sigma_{\mathrm{abs}}\right)$ and (c) mass absorption cross section (MAC).

The number size distribution followed the lognormal distribution and peaked at $122 \mathrm{~nm}$ (CMD) (Fig. 4a). Because most $r \mathrm{BC}$ particles (by number) emitted from urban areas were below the SP2 detection limit of $70 \mathrm{~nm}$, the comparison of the number size distribution between urban and rural areas was meaningless (Schwarz et al., 2008). There was snowfall with the intensity of $0.23 \mathrm{~mm} \mathrm{~h}^{-1}$ during the observation period, and the mass and number size distributions of the $r \mathrm{BC}$ core mass equivalent diameter $\left(D_{\mathrm{c}}\right)$ during the snow event are illustrated in Fig. 4b and c. During before-snow, snow, and after-snow periods, the MMD was 213, 210, and $206 \mathrm{~nm}$, a decrease by $3.3 \%$, and the CMD was 120,126 , and $129 \mathrm{~nm}$, an increase of $7.5 \%$, respectively. We found that the number size distribution during the pre-snow and after-snow periods was consistent with a log-normal distribution. CMD of fresh BC usually ranges from 50 to $80 \mathrm{~nm}$ (Bond et al., 2013), so we extrapolated the fitting curves to $10 \mathrm{~nm}$ (Fig. 4c). The difference in areas between the two log-normal fit curves at $D_{\mathrm{c}}$ less than $121 \mathrm{~nm}$ was 0.23 ; that is, the amount of $r \mathrm{BC}$ with $D_{\text {c }}$ less than $121 \mathrm{~nm}$ decreased by $28.4 \%$ after snow. According to Fig. 3, the number concentration of $r \mathrm{BC}$ with $D_{\mathrm{c}}$ below $100 \mathrm{~nm}$ decreased significantly, while the number concentration of $r \mathrm{BC}$ with $D_{\mathrm{c}}$ about $200 \mathrm{~nm}$ decreased slightly during the snow case. This result is similar to the observation in Beijing that the snow with a precipitation intensity of $0.37 \mathrm{~mm}$ reduced the volume concentration of the small particle size $(<100 \mathrm{~nm})$ fraction in the accumulation mode (Su et al., 2016). Previous studies found that wet deposition is the main mechanism for removing $r \mathrm{BC}$-containing particles (Taylor et al., 2014). Wet removal plays an important role in determining the size distribution of $r \mathrm{BC}$ during vertical transport in the free troposphere (Moteki et al., 2012), and rainfall, as a means of wet removal, preferentially removes large $r \mathrm{BC}$-containing particles, resulting in a decrease in MMD after rain events (Liu et al., 2020b; Wang et al., 2018). However, the snow with relatively weak intensity may preferentially remove the small core size of $r \mathrm{BC}$. Although the CMD increased moderately, the effect of removing $r \mathrm{BC}$ particles with a small core size $\left(D_{\mathrm{c}}\right)$ by snow was insignificant on the MMD (Liu et al., 2020a). The mechanism of wet scavenging and its effect of the distribution of aerosol particle size are complex (X. Zhao et al., 2020c; Sun et al., 2019), and we will investigate in more depth how wet scavenging affects $r \mathrm{BC}$ particle size in a future study.

\subsection{Mixing state of $r \mathrm{BC}$-containing particles under different conditions}

\subsubsection{Coating thickness of $r \mathrm{BC}$-containing particles}

Figure 5 provides the temporal variation of ACT, RCT, and $\mathrm{CMD}$ of $r \mathrm{BC}$-containing particles during the entire period. The relative coating thickness (RCT) and absolute coating thickness of $r \mathrm{BC}$-containing particles were calculated by the LEO fitting method; see Sect. 2.2.2 for details. Herein, $r \mathrm{BC}$ cores with $D_{\mathrm{c}}=180 \pm 10 \mathrm{~nm}$ and $D_{\mathrm{c}}=$ $190 \pm 10 \mathrm{~nm}$ were selected because the low scattering signal of small $r \mathrm{BC}$ is easily influenced by signal noise (Schwarz et al., 2008; G. Zhao et al., 2020; Liu et al., 2020b). The average RCT $( \pm 1 \sigma)\left(D_{\mathrm{c}} @ 170-190 \mathrm{~nm}\right)$ was $1.6( \pm 0.2)$, $\mathrm{RCT}( \pm 1 \sigma)\left(D_{\mathrm{c}} @ 190-210 \mathrm{~nm}\right)$ was $1.5( \pm 0.2), \mathrm{ACT}( \pm 1 \sigma)$ $\left(D_{\mathrm{c}} @ 170-190 \mathrm{~nm}\right)$ was $52.4( \pm 21.8) \mathrm{nm}$, and ACT $( \pm 1 \sigma)$ $\left(D_{\mathrm{c}} @ 190-210 \mathrm{~nm}\right)$ was $54.2( \pm 20.4) \mathrm{nm}$. As shown in Table 1, the RCT ( $D_{\mathrm{c}} @ 190-210 \mathrm{~nm}$ ) of the GC site was consistent with the RCT (1.2-1.4) with $D_{\mathrm{c}}=200 \mathrm{~nm}$ of $r \mathrm{BC}$ - 

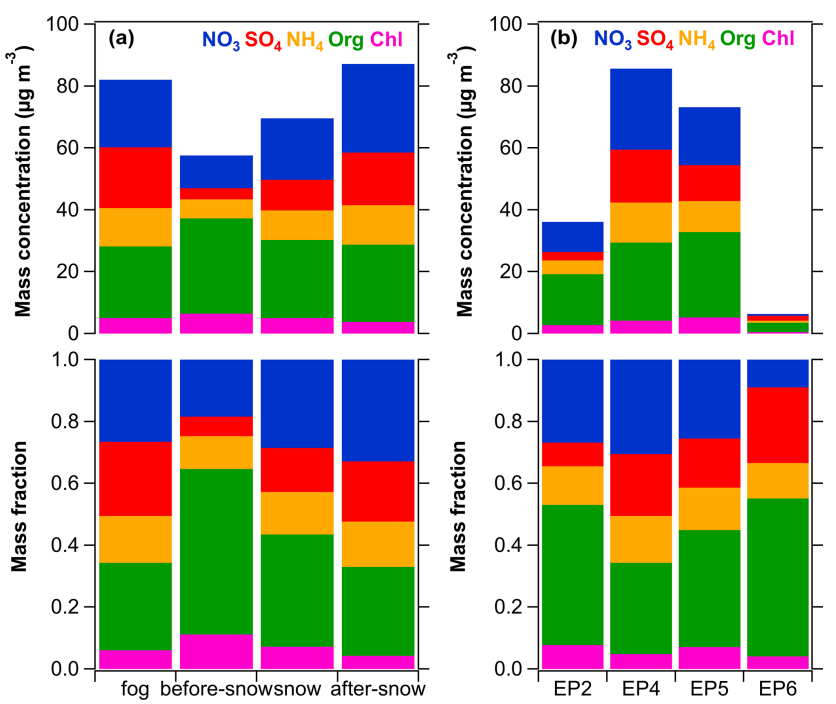

Figure 6. Changes in mass concentration and mass fractions of aerosol species during different periods.

containing particles emitted from biomass burning through laboratory research (Pan et al., 2017) but was larger than the value $\left(\mathrm{RCT}\left(@ D_{\mathrm{c}}=180 \mathrm{~nm}\right)=1.2\right)$ during the summer in Beijing, which was mainly influenced by traffic emissions (Liu et al., 2020b). The ACT at the GC site $\left(D_{\mathrm{c}} @ 190\right.$ $210 \mathrm{~nm})$ was smaller than the ACT $\left(@ D_{\mathrm{c}}=200 \mathrm{~nm}\right)$ affected by biomass burning $(65 \mathrm{~nm})$ in Texas and larger than the ACT (@ $D_{\mathrm{c}}=200 \mathrm{~nm}$ ) affected by urban emissions in Texas (Schwarz et al., 2008). The different sources and aging processes of $r \mathrm{BC}$-containing particles affect the coatings. Laborde et al. (2013) reported that $r \mathrm{BC}$-containing particles emitted by traffic were essentially uncoated, with a median coating thickness of $2 \pm 10 \mathrm{~nm}$ at a core size of 180 $220 \mathrm{~nm}$, the median ACT of $r$ BC-containing particles emitted by biomass burning was approximately $20-40 \mathrm{~nm}$, and the median $\mathrm{ACT}$ of $r \mathrm{BC}$-containing particles in continental aged air masses reached $\sim 80 \mathrm{~nm}$.

In addition, we compared the average coating thickness of $r$ BC-containing particles during different periods. As shown in Table S2, the average RCT and ACT $( \pm 1 \sigma)\left(D_{\mathrm{c}} @ 170\right.$ $190 \mathrm{~nm})$ were $2.0( \pm 0.3)$ and $92.7( \pm 23.8) \mathrm{nm}$, respectively, during the fog event, which were the highest values during the whole observation period. During the beforesnow, snow, and after-snow periods, the average RCTs (ACTs) $( \pm 1 \sigma)\left(D_{\mathrm{c}} @ 170-190 \mathrm{~nm}\right)$ were $1.4( \pm 0.1)(39.9$ $( \pm 43.6) \mathrm{nm}), 1.5( \pm 0.1)(46.9( \pm 4.5) \mathrm{nm})$, and $1.7( \pm 0.1)$ $(61.3( \pm 4.7) \mathrm{nm})$, respectively. During the polluted periods (EP2, EP4, and EP5), the average RCTs (ACTs) $( \pm 1 \sigma)$ $\left(D_{\mathrm{c}} @ 170-190 \mathrm{~nm}\right)$ were $1.5( \pm 0.1)(42.3( \pm 9.4) \mathrm{nm}), 1.7$ $( \pm 0.1)(58.6( \pm 12.7) \mathrm{nm})$, and $1.6( \pm 0.2)(37.0( \pm 9.5) \mathrm{nm})$, respectively. The average RCT and ACT $( \pm 1 \sigma)\left(D_{\mathrm{c}} @ 170\right.$ $190 \mathrm{~nm})$ were $1.4( \pm 0.1)$ and $37.0( \pm 9.5) \mathrm{nm}$ during the clean period (EP6). We used the ambient mass concentra- tions of NR-PM1 and meteorological conditions to discuss the differences in coating thickness during different periods. According to Fig. 6, the ambient mass concentrations of total NR-PM1 were almost the same during the fog, after-snow, and EP4 periods. However, the coating thickness was different. The RH during these three periods was different, where the RH during the fog event was highest $(\mathrm{RH}=100 \%)$, the RH during EP4 was lowest (RH $\sim 81 \%$ ), and the RH during the after-snow period was about $96 \%$. In addition, the concentrations and mass fractions of ambient sulfate and organics during fog events were the highest and lowest, respectively, in the three cases. This indicates that a high RH significantly affected the formation of coatings under the same concentration of pollutants in the atmosphere. Moreover, it was also likely that the high RH provides favorable conditions for the sulfate formed by the aqueous-phase reaction. This also means that the high fraction of sulfate and low fraction of organics in the environment provide favorable conditions for the formation of coatings. This is similar to the conclusion obtained from previous studies; the increase of growth factor of $\mathrm{BC}\left(\mathrm{gf}_{\mathrm{BC}}\right)$ was positively associated with the elevation of secondary inorganic material, while it was suppressed by the increase of organic coating content (Liu et al., 2013). The changes of the coatings and variations of the NR-PM1 fractions in the environment were also consistent with this pattern. The secondary transformation of inorganic aerosols was intensified due to the increasing ambient RH during snowfall. The increase in the fraction of secondary inorganic aerosols in the atmosphere and the decrease in the fraction of organic materials and chlorides to a certain extent favor the formation of $r \mathrm{BC}$ coatings. Similarly, the coating thickness of $r \mathrm{BC}$-containing particles showed a positive variation with $\mathrm{RH}$ and the fractions of secondary inorganic aerosols during the selected pollution periods (EP2, $\mathrm{EP} 4$, and EP5). Despite the higher concentration of $r \mathrm{BC}$ during EP2, the lower RH and the fraction of secondary inorganic aerosols during this period result in thinner coatings of $r \mathrm{BC}$-containing particles, indicating that pollution processes based on primary emissions were not conducive to the formation of $r \mathrm{BC}$ coatings. During dry, clean days, both primary emissions and secondary transformation were weak, and the coating thickness of $r \mathrm{BC}$-containing particles was relatively thinner compared with periods of pollution days under high$\mathrm{RH}$ conditions. This part of $r \mathrm{BC}$-containing particles constitutes mainly aged $r \mathrm{BC}$ that has not been scavenged.

\subsubsection{Absorption enhancement of $r \mathrm{BC}$-containing particles}

The $E_{\mathrm{abs}}, \sigma_{\mathrm{abs}}$, and MAC of $r \mathrm{BC}$-containing particles during the whole campaign are shown in Fig. 5. The average $E_{\text {abs }}$ and $\mathrm{MAC}$ at $880 \mathrm{~nm}$ were 1.3 and $5.5 \mathrm{~m}^{2} \mathrm{~g}^{-1}$, respectively, as calculated by Mie theory. Comparisons of $E_{\text {abs }}$ in various field studies are shown in Table 2. The $E_{\text {abs }}$ values at the GC site we simulated were consistent with the value measured 
Table 2. Comparisons of $E_{\mathrm{abs}}$ in various field studies.

\begin{tabular}{lllcl}
\hline Method & Location & Time & $E_{\text {abs }}(\lambda$ nm) & Reference \\
\hline TD + PAX + HR-AMS + AE33 & Gucheng, China (rural) & December 2019-January 2020 & $1.32 \pm 0.15(870)$ & Sun et al. (2021) \\
TD + PAX + SP2+ AMS & California, USA (urban) & January-February 2013 & $1.21 \pm 0.09(870)$ & Zhang et al. (2016) \\
SP2+ CPMA + DMA & Beijing, China (Urban) & May-June 2018 & $1.15(550)$ & Liu et al. (2020) \\
SP2+ PAX + ACSM & Xi'an, China (urban) & December 2012-January 2013 & $1.8(870)$ & Wang et al. (2014) \\
AE33+ ACSM + OC/EC & Paris, France (suburban) & March 2014-March 2017 & $1.53 \pm 0.93(880)$ & Zhang et al. (2018a) \\
TD + BBCES + IS & Shouxian, China (rural) & June-July 2016 & $2.3 \pm 0.9(532)$ & Xu et al. (2018) \\
AFD & Yuncheng, China (rural) & June-July 2014 & $2.25 \pm 0.55(678)$ & Cui et al. (2016) \\
SP2 & Gucheng, China (rural) & December 2019 & $1.33 \pm 0.57(880)$ & This work \\
\hline
\end{tabular}

by Sun et al. (2021) with TD-PAX (Droplet Measurement Technologies) at $870 \mathrm{~nm}(1.32 \pm 0.15)$. The $E_{\text {abs }}$ calculated by Mie theory is only related to the core size of $r \mathrm{BC}$, the refractive index of $r \mathrm{BC}$-containing particles, and the coating thickness. It has been suggested that the correlation between $\sigma_{\text {abs }}$ calculated by Mie theory and $\sigma_{\text {abs }}$ measured by AE33 is as high as 0.98 , indicating that the optical properties of $r \mathrm{BC}$-containing particles calculated by Mie theory can represent the actual $r$ BC-containing particles in a specific area (Zhang et al., 2018a). Therefore, we compared the differences in $E_{\text {abs }}$ between the GC site and other regions. A moderate $E_{\text {abs }}(1.21 \pm 0.09)$ at $870 \mathrm{~nm}$ was found in California during winter in 2013 which was close to the present study (Zhang et al., 2016). The $E_{\text {abs }}$ were slightly larger than the value simulated using core-shell in Beijing during summer in 2008 at $550 \mathrm{~nm}$ (1.15) (Liu et al., 2020b). Slightly high $E_{\text {abs }}$ values were observed in Xi' an (1.8 at $870 \mathrm{~nm}$ ) (Wang et al., 2014) and Paris (1.53 \pm 0.93 at $880 \mathrm{~nm}$ ) (Zhang et al., $2018 \mathrm{~b}$ ), which represent the more polluted urban areas. Previous studies have found that the $E_{\text {abs }}$ values are generally higher in rural areas than in urban areas, such as Shouxian $(2.3 \pm 0.9$ at $532 \mathrm{~nm})(\mathrm{Xu}$ et al., 2018) and Yuncheng $(2.25 \pm 0.55$ at $678 \mathrm{~nm})$ (Cui et al., 2016). In addition, we studied the absorption enhancement of $r$ BC-containing particles during six different periods, and specific information is detailed in Table S1 in the Supplement. From the beforesnow to after-snow period, the coating thickness and $E_{\text {abs }}$ of $r \mathrm{BC}$-containing particles increased gradually. During the clean period, $r \mathrm{BC}$ with a larger core size was mostly emitted from primary sources, and the $E_{\text {abs }}$ was close to 1 . In the fog event, the coating thickness was the highest among the six periods, while the $E_{\text {abs }}$ was lower. This may be because the core size $\left(D_{\mathrm{c}}\right)$ of $r \mathrm{BC}$ during fog events was larger, $r \mathrm{BC}$ with a large core size $\left(D_{\mathrm{c}}\right)$ had a lower MAC, and the addition of coatings to $r \mathrm{BC}$ with a large $D_{\mathrm{c}}$ did not significantly affect the final total MAC compared to $r$ BC with a small $D_{\mathrm{c}}$ (Liu et al., 2019). Compared with other rural sites, the $E_{\mathrm{abs}}$ and MAC of $r$ BC-containing particles at the GC site were low. Sun et al. (2021) found that the absorption due to the lensing effect at the GC site correlated best with chloride and less well with secondary inorganic aerosol (SIA) and secondary organic aerosol (SOA). Chloride is mainly from coal com- bustion and biomass burning emissions, which means that the $E_{\text {abs }}$ values at the GC site of $r$ BC-containing particles were dominantly affected by primary species and that the coatings formed by secondary reaction products had little effect on $E_{\text {abs }}$. This result was consistent with the findings observed at Fresno with similar emission sources as the GC site, where the average mixing-induced absorption enhancement of $\mathrm{BC}$ due to the coatings can be very small (Cappa et al., 2019).

\subsection{Diurnal variation of the mixing state of $r \mathrm{BC}$}

Figure 7 exhibits the diurnal trend of the mixing state of $r \mathrm{BC}$ containing particles. The temporal variation in $r \mathrm{BC}$ exhibited a clear U-shaped pattern, while the diurnal variation in wind speed was the opposite (Fig. S3). The mean $r$ BC mass loading increased during the evening, with a peak $\left(3.5 \mu \mathrm{g} \mathrm{m}^{-3}\right)$ at 20:00 LST and a minimum $\left(1.4 \mu \mathrm{g} \mathrm{m}^{-3}\right)$ at 16:00 LST at the GC site, which was later than that in Beijing (Xie et al., 2020). From the diurnal variation of wind speed (Fig. S3), it can be seen that the wind speed started to increase at approximately 09:00 LST and reached a maximum $\left(2.2 \mathrm{~ms}^{-1}\right)$ at 13:00 LST. These two time points corresponded to the start of $r \mathrm{BC}$ decline and the lowest value of $r \mathrm{BC}$ respectively. This diurnal variation in $r \mathrm{BC}$ and wind speed can be explained by the diurnal variation in the boundary layer (Simpson and McGee, 2012; Talukdar et al., 2019). In the early morning, calm inversion conditions predominate in the boundary layer. The temperature rose, the wind speed increased to an average of over $2 \mathrm{~ms}^{-1}$ at midday, and the $r \mathrm{BC}$ declined rapidly with decreased atmospheric stability and increased turbulence. After sunset, the temperature dropped sharply, due to inversion and increased emissions from heating activities, and the surface pollution of $r \mathrm{BC}$ was enhanced. The diurnal cycle of $\sigma_{\mathrm{abs}}$ was similar to that of $r \mathrm{BC}$ mass concentration, which may be because $\sigma_{\mathrm{abs}}$ values of $r \mathrm{BC}$ depend on its concentration (Zhang et al., 2018b). MAC and $D_{\text {c }}$ did not show significant diurnal variations. The coating thickness of freshly emitted $r \mathrm{BC}$-containing particles was thin but thicker through a complex aging process, indicating that the RCT was controlled by the competing effects of the aging process and emissions. The temporal variation in RCT did not present a clear inverted U-shaped pattern like Beijing during 

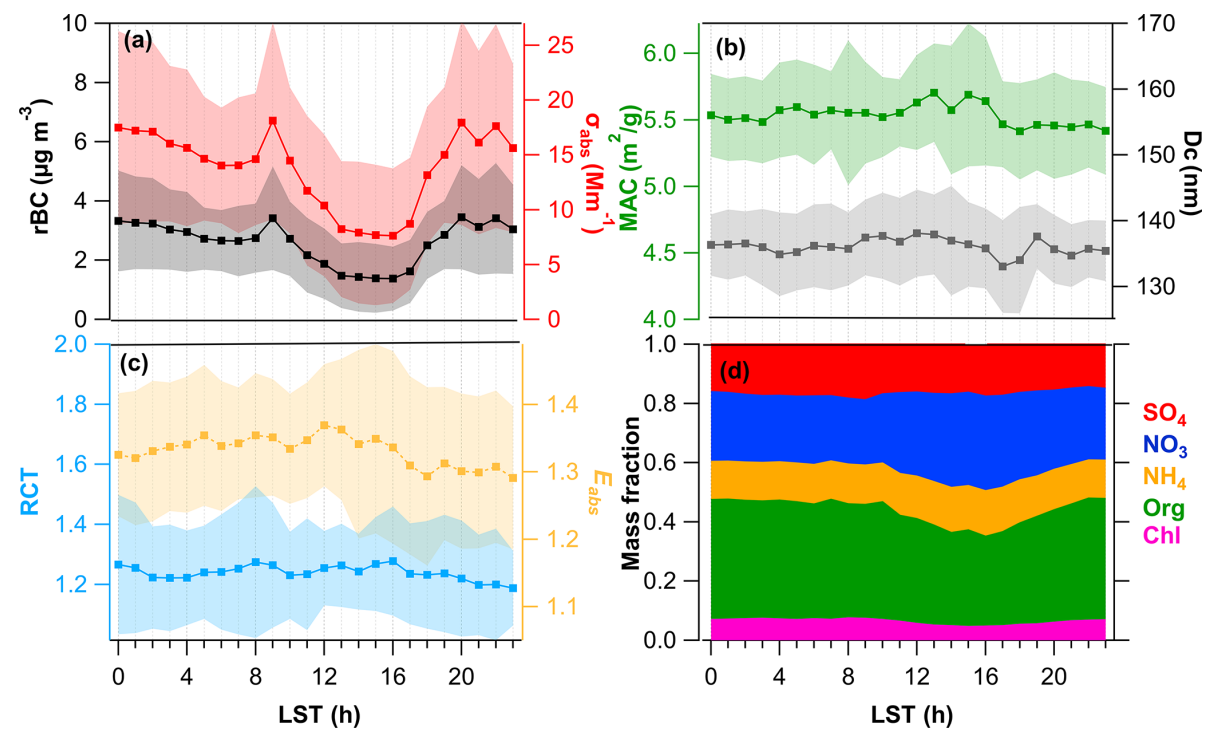

Figure 7. Diurnal variation in (a) $r \mathrm{BC}$ mass loading and absorption coefficients $\left(\sigma_{\mathrm{abs}}\right)$ of $r$ BC-containing particles, (b) the mass absorption cross section (MAC) of $r$ BC-containing particles and the MMD, and (c) relative coating thickness $\left(\mathrm{RCT} @ D_{\mathrm{c}}=180 \mathrm{~nm}\right)$ and absorption enhancement $\left(E_{\mathrm{abs}}\right)$ of $r \mathrm{BC}$. The shaded areas denote the standard deviation. (d) Mass fraction of aerosol species.

summer (Liu et al., 2020b). Three peaks of the mean RCT appeared at 00:00, 08:00, and 18:00, indicating that $r \mathrm{BC}$ emissions increased after 00:00, 08:00, and 18:00 at the GC site, and fresh $r \mathrm{BC}$ decreased the coating thickness. In addition, there was a significant increase in RCT from the late afternoon. The light absorption enhancement of $r \mathrm{BC}$ also did not present a strong diurnal variation trend like Beijing during June (Xie et al., 2019). This trend was consistent with the diurnal variation trend of MAC but different from that of RCT. As shown in Fig. S4, a good correlation was found between MAC $(880 \mathrm{~nm})$ and $E_{\mathrm{abs}}$, with an $R^{2}$ of 0.75 , and a weak anticorrelation was found between RCT and $E_{\text {abs }}$, with an $R^{2}$ of 0.14 . This is consistent with the results discussed in Sect. 3.3.2, where the $E_{\text {abs }}$ values at the GC site were more influenced by the MAC of the $r \mathrm{BC}$ than the coating thickness. The diurnal variation in the mass fraction of aerosol species is shown in Fig. 7d. The daily cycle of mass fractions in chloride, organics, and ammonium began to decrease in the late afternoon, while nitrate increased. The two higher diurnal peak values of the mass fraction of sulfate occurred at 09:00 and 16:00 LST, and the daily variation peak of the mass fraction of nitrate occurred at 16:00 LST. This may explain the increase in RCT in the late afternoon, and an increase in the mass fraction of sulfate and nitrate in the environment may favor an increase in the coating thickness of $r \mathrm{BC}$-containing particles. However, the diurnal cycle of light absorption enhancement of $r \mathrm{BC}$ presented limited dependence on the aerosol species in the environment.

\subsection{The dependence of the aging degree of $r$ BC-containing particles on meteorological and pollution conditions}

The factors that affect the aging degree of $r \mathrm{BC}$-containing particles include photochemical reactions, chemical coatings, and the meteorology of the environment (Laborde et al., 2013; Saathoff et al., 2003; Schnaiter, 2005). Here, we select $r$ BC-containing particles with a $D_{\mathrm{c}}$ size of $170-190 \mathrm{~nm}$. Figure 8 shows RCT as a function of temperature and $\mathrm{RH}$. Temperature and $\mathrm{RH}$ ranged from -14 to $8{ }^{\circ} \mathrm{C}$ and from $9 \%$ to $100 \%$, respectively. In general, the changes of RH were mainly controlled by diurnal variations in temperature (Fig. S3). The higher the RH, the greater the RCT at the same temperature. At temperatures lower than $-8^{\circ} \mathrm{C}$, the $\mathrm{RH}$ was lower than $60 \%$, and the RCT was smaller than 1.5. However, in the intermediate temperature regime $\left(-7-4^{\circ} \mathrm{C}\right)$, the RH required when the RCT exceeds 1.6 decreases with the increase of temperature. Larger RCT $(\mathrm{RCT}>2)$ occurred in the temperature range of $-4-4{ }^{\circ} \mathrm{C}$ when the $\mathrm{RH}$ was higher than $50 \%$, indicating that lower $\mathrm{RH}(\sim 60 \%)$ is required for $r \mathrm{BC}$ to form thick coatings under the subcooled condition $\left(0^{\circ} \mathrm{C} \leq T<8{ }^{\circ} \mathrm{C}\right)$, while higher $\mathrm{RH}(\sim 80 \%)$ is required for $r \mathrm{BC}$ to form thick coatings under the supercooled condition $\left(-14^{\circ} \mathrm{C}<T<0^{\circ} \mathrm{C}\right)$.

In order to exclude the influence of special cases on the general results, data from fog days and snow periods were excluded to further investigate the aging of $r \mathrm{BC}$. Based on the normalized frequency of data points under different $\mathrm{RH}$ and temperature ranges (Fig. 9d), five RH levels of $0 \%-$ $30 \%, 30 \%-40 \%, 40 \%-50 \%, 50 \%-60 \%$, and $60 \%-100 \%$ were selected in two different temperature ranges (super- 


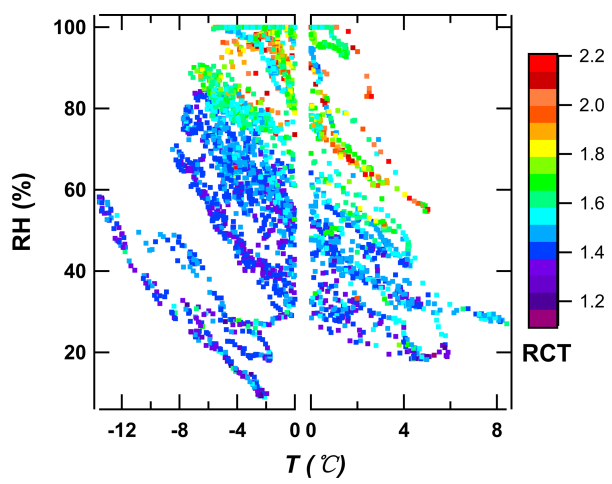

Figure 8. RCT as a function of temperature and RH.
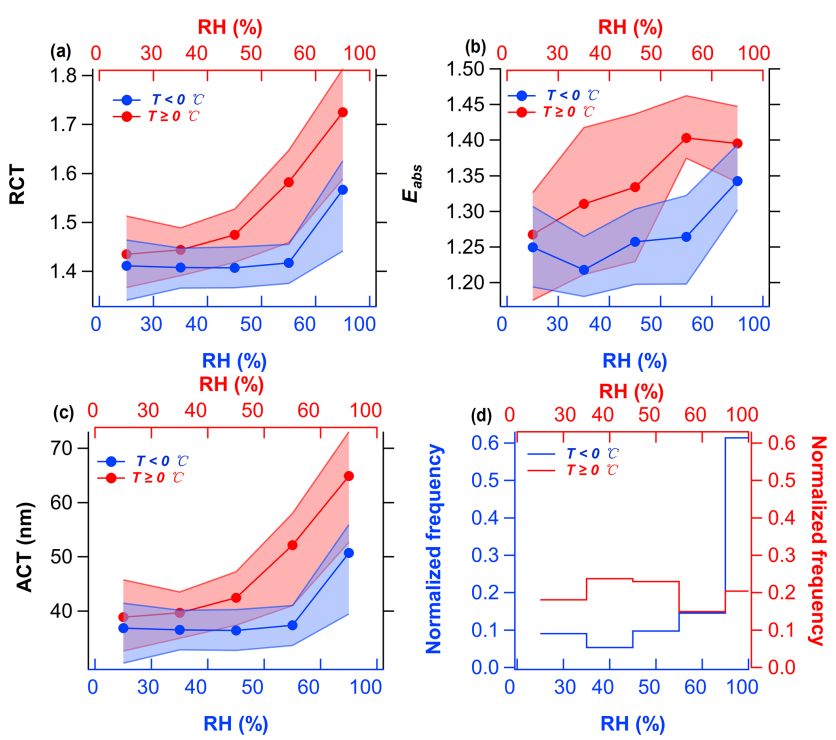

Figure 9. (a-c) RCT ( $\left.D_{\mathrm{c}} @ 180 \mathrm{~nm}\right), E_{\mathrm{abs}}$, and ACT ( $\left.D_{\mathrm{c}} @ 180 \mathrm{~nm}\right)$ dependence on $\mathrm{RH}$ under the temperature regimes of $-14^{\circ} \mathrm{C}<$ $T<0^{\circ} \mathrm{C}$ and $0{ }^{\circ} \mathrm{C}<T<8^{\circ} \mathrm{C}$. Circles represent the average values. The upper and lower boundaries of the shaded areas represent the 75th and 25th percentiles of data points in each bin. (d) The normalized frequency of data points in each bin under different temperature ranges.

cooled condition $\left(-14^{\circ} \mathrm{C}<T<0^{\circ} \mathrm{C}\right)$ and subcooled condition $\left.\left(0^{\circ} \mathrm{C} \leq T<8^{\circ} \mathrm{C}\right)\right)$ to investigate the dependence of the mixing state of $r \mathrm{BC}$ on temperature and $\mathrm{RH}$. The mean RCT, $E_{\text {abs }}$, ACT, and aerosol species as a function of RH for two different temperature regimes were shown in Figs. 9 and 10. The average RCT increased from $\sim 1.4$ to 1.6 and from $\sim 1.4$ to 1.7 , and the average ACT increased from $\sim 37$ to $51 \mathrm{~nm}$ and from $\sim 39$ to $65 \mathrm{~nm}$ at the GC site as RH increased from 0 to $100 \%$ under the supercooled condition and subcooled condition, respectively. The coating thickness of $r \mathrm{BC}$ particles was thicker under subcooled conditions than under supercooled conditions. This indicates that a suitable high temperature is conducive to the aging of $r \mathrm{BC}$ particles. This variation was also supported by the gradual increases
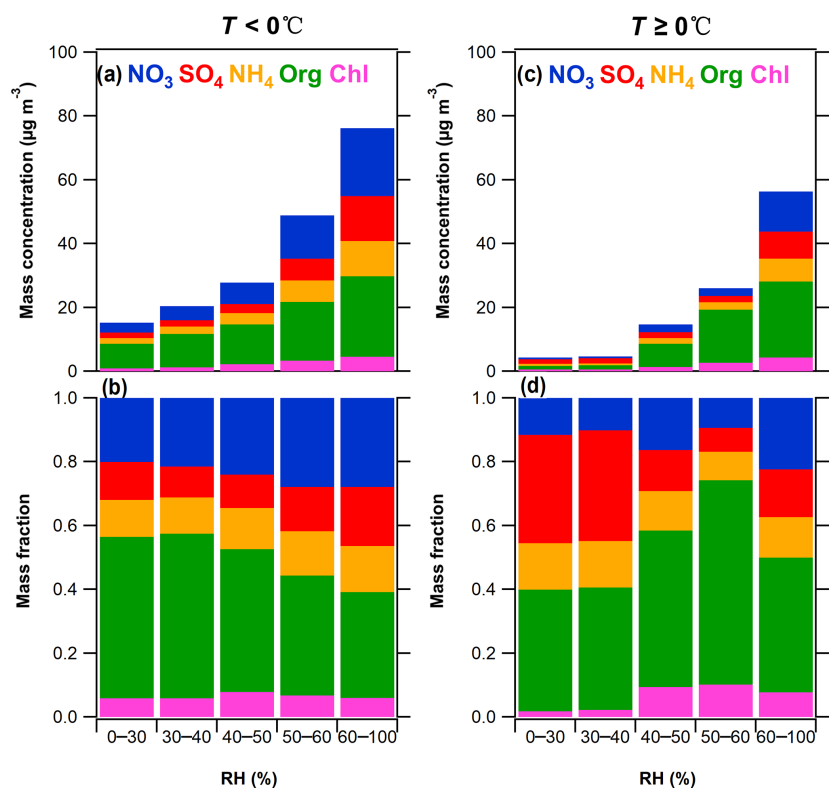

Figure 10. Mass concentration and mass fractions of aerosol species dependence on $\mathrm{RH}$ at different temperature ranges. Panel (a) and (b) denote the situation for $-14^{\circ} \mathrm{C}<T<0^{\circ} \mathrm{C}$. Panels (c) and (d) denote the situation for $0^{\circ} \mathrm{C}<T<8^{\circ} \mathrm{C}$.

in mass concentration and mass fractions of secondary components as a function of RH in the environment. Under subcooled conditions, the coating thickness of $r \mathrm{BC}$ started to increase significantly at $\mathrm{RH}>40 \%$, whereas this phenomenon did not occur until RH $>60 \%$ under supercooled conditions. This show that the $\mathrm{RH}$ required to form a thicker coating of $r \mathrm{BC}$ particles was lower under subcooled conditions. The high mass fraction of secondary components formed by liquid phase and heterogeneous reactions in the environment under high-RH and subcooled conditions were favorable to form coatings of $r$ BC particles (Collier et al., 2018; Wu et al., 2016).

The RH dependence of average $E_{\text {abs }}$ is shown in Fig. 9b. The RH dependence of $E_{\text {abs }}$ was likely caused by the RCT as supported by the gradual increase in the mass concentration and mass fraction of secondary components as a function of RH in the ambient (Fig. 10a and b). The average $E_{\text {abs }}$ increased from $\sim 1.2$ to 1.3 and from 1.3 to 1.4 as $\mathrm{RH}$ increased from 0 to $100 \%$ under the supercooled condition and subcooled condition, respectively. The $E_{\text {abs }}$ under subcooled conditions was greater than that under supercooled conditions. The average $E_{\text {abs }}$ remained almost constant after RH exceeded $60 \%$ under subcooled conditions. We suspected that the contribution of the aqueous-phase formation of secondary components to $E_{\text {abs }}$ might be limited under high RH (Sun et al., 2021). 


\section{Conclusions}

The size distribution, coating thickness, and optical properties of individual $r \mathrm{BC}$-containing particles were measured by a single-particle soot photometer (SP2) during the period 7 to 31 December 2019 to characterize the mixing state of $r$ BC-containing particles in rural areas on the North China Plain. There were fog, snow, and heavy pollution events during the observation period, so we analyzed the mixing state and optical properties of $r \mathrm{BC}$-containing particles in different episodes and discussed the factors affecting the aging degree of $r \mathrm{BC}$. The mean mass concentration of $r \mathrm{BC}$ at the $\mathrm{GC}$ site was $2.6( \pm 1.5) \mu \mathrm{g} \mathrm{m}^{-3}$, which was much lower than the observations in the winter of 2016 and 2018 at the urban site in Beijing. The MMD and CMD of $r \mathrm{BC}$ at the GC site were 213 and $122 \mathrm{~nm}$, respectively. The MMD was smaller than that in other rural areas. In addition to the impact of emission sources, meteorological conditions can significantly affect the size distribution of $r \mathrm{BC}$. The CMD of $r \mathrm{BC}$ increased after snow, suggesting that snow events with the light intensity $\left(0.23 \mathrm{~mm} \mathrm{~h}^{-1}\right)$ preferred to remove $r \mathrm{BC}$-containing particles with smaller core sizes. The average RCT (ACT) was $1.6(52 \mathrm{~nm})$ when the $D_{\mathrm{c}}$ was in the range of $170 \sim 190 \mathrm{~nm}$, indicating a moderate coating thickness of $r \mathrm{BC}$ during the winter. The coating thickness of $r \mathrm{BC}$-containing particles in the fog event was thicker than that in other periods due to the high RH and high concentrations of secondary aerosols. When the concentrations of NR-PM1 in the environment were the same in the different cases, the higher the RH, the thicker the coating thickness. Higher mass fractions of secondary inorganic aerosols (SIAs) and lower mass fractions of organics in the environment may favor the formation of coatings of $r \mathrm{BC}$. The ensemble-average mixing-induced $E_{\text {abs }}$ (1.3) and MAC $\left(5.5 \mathrm{~m}^{2} \mathrm{~g}^{-1}\right)$ at the GC site were smaller than those in other rural areas. The RCT and $E_{\text {abs }}$ did not show clear diurnal cycles, with little variation in the range of $\sim 1.9-2$ and 1.3-1.4, respectively. A good correlation was found between MAC $(880 \mathrm{~nm})$ and $E_{\text {abs }}$, with an $R^{2}$ of 0.75 , and a weak anticorrelation was found between RCT and $E_{\mathrm{abs}}$, with an $R^{2}$ of 0.14 under diurnal cycle. This may be because the optical properties of $r \mathrm{BC}$ at the $\mathrm{GC}$ site were mainly influenced by primary emissions (such as coal combustion, biomass burning, and traffic emission), and the absorption due to the lensing effect contributes less to it.

Our results showed that the mixing state of $r \mathrm{BC}$ containing particles depends on the synergistic effects of ambient RH, temperature, and aerosol species. Higher RH made it easier for $r \mathrm{BC}$ to form thicker coatings when the ambient temperature was the same. At temperatures lower than $-8^{\circ} \mathrm{C}$, the RH was lower than $60 \%$, and the RCT was smaller than 1.5. Larger RCT $(\mathrm{RCT}>2)$ occurred in the temperature range of $-4-4{ }^{\circ} \mathrm{C}$ when the $\mathrm{RH}$ was higher than $50 \%$. The RH required to form the same coating thickness of $r \mathrm{BC}$ was higher under supercooled conditions than that under subcooled conditions. The RH dependence of $E_{\mathrm{abs}}$ was likely caused by the RCT as supported by the gradual increase in the mass concentration and mass fraction of secondary components as a function of RH in the ambient. The mass fractions of aqueous-phase formation of secondary components had a limited effect on $E_{\text {abs }}$ under a high-RH environment. The increasing mass fraction of secondary components in the environment favored the aging of $r \mathrm{BC}$ under high-RH, subcooled conditions. Our results highlight that the aging degree of $r \mathrm{BC}$ in different meteorological environments needs to be considered in regional climate models to better evaluate the radiative forcing of $r \mathrm{BC}$.

Data availability. To request the data given in this study, please contact Xiaole Pan at the Institute of Atmospheric Physics, Chinese Academy of Sciences, via email (panxiaole@mail.iap.ac.cn).

Supplement. The supplement related to this article is available online at: https://doi.org/10.5194/acp-21-17631-2021-supplement.

Author contributions. YZ, SL, HL, and XP designed the research. YZ, SL, HL, XP, WX, YT, WY, XL, QL, JL, CC, YS, PF, JX, JC, and ZW performed the experiments. YZ, SL, HL, and XP performed the data analysis. YZ, HL, XP, and SL wrote the paper.

Competing interests. The contact author has declared that neither they nor their co-authors have any competing interests.

Disclaimer. Publisher's note: Copernicus Publications remains neutral with regard to jurisdictional claims in published maps and institutional affiliations.

Financial support. This research has been supported by the National Natural Science Foundation of China (grant no. 41877314).

Review statement. This paper was edited by Ottmar Möhler and reviewed by three anonymous referees. 


\section{References}

Baumgardner, D., Popovicheva, O., Allan, J., Bernardoni, V., Cao, J., Cavalli, F., Cozic, J., Diapouli, E., Eleftheriadis, K., Genberg, P. J., Gonzalez, C., Gysel, M., John, A., Kirchstetter, T. W., Kuhlbusch, T. A. J., Laborde, M., Lack, D., Müller, T., Niessner, R., Petzold, A., Piazzalunga, A., Putaud, J. P., Schwarz, J., Sheridan, P., Subramanian, R., Swietlicki, E., Valli, G., Vecchi, R., and Viana, M.: Soot reference materials for instrument calibration and intercomparisons: a workshop summary with recommendations, Atmos. Meas. Tech., 5, 1869-1887, https://doi.org/10.5194/amt-5-1869-2012, 2012.

Bond, T. C., Doherty, S. J., Fahey, D. W., Forster, P. M., Berntsen, T., DeAngelo, B. J., Flanner, M. G., Ghan, S., Kärcher, B., Koch, D., Kinne, S., Kondo, Y., Quinn, P. K., Sarofim, M. C., Schultz, M. G., Schulz, M., Venkataraman, C., Zhang, H., Zhang, S., Bellouin, N., Guttikunda, S. K., Hopke, P. K., Jacobson, M. Z., Kaiser, J. W., Klimont, Z., Lohmann, U., Schwarz, J. P., Shindell, D., Storelvmo, T., Warren, S. G., and Zender, C. S.: Bounding the role of black carbon in the climate system: A scientific assessment, J. Geophys. Res.Atmos., 118, 5380-5552, https://doi.org/10.1002/jgrd.50171, 2013.

Cao, G., Zhang, X., and Zheng, F.: Inventory of black carbon and organic carbon emissions from China, Atmos. Environ., 40, 65166527, https://doi.org/10.1016/j.atmosenv.2006.05.070, 2006.

Cappa, C. D., Onasch, T. B., Massoli, P., Worsnop, D. R., Bates, T. S., Cross, E. S., Davidovits, P., Hakala, J., Hayden, K. L., Jobson, B. T., Kolesar, K. R., Lack, D. A., Lerner, B. M., Li, S.-M., Mellon, D., Nuaaman, I., Olfert, J. S., Petaja, T., Quinn, P. K., Song, C., Subramanian, R., Williams, E. J., and Zaveri, R. A.: Radiative Absorption Enhancements Due to the Mixing State of Atmospheric Black Carbon, Science, 337, 1078-1081, https://doi.org/10.1126/science.1223447, 2012.

Cappa, C. D., Zhang, X., Russell, L. M., Collier, S., Lee, A. K. Y., Chen, C.-L., Betha, R., Chen, S., Liu, J., Price, D. J., Sanchez, K. J., McMeeking, G. R., Williams, L. R., Onasch, T. B., Worsnop, D. R., Abbatt, J., and Zhang, Q.: Light Absorption by Ambient Black and Brown Carbon and its Dependence on Black Carbon Coating State for Two California, USA, Cities in Winter and Summer, J. Geophys. Res.-Atmos., 124, 1550-1577, https://doi.org/10.1029/2018jd029501, 2019.

Cherian, R., Quaas, J., Salzmann, M., and Tomassini, L.: Black carbon indirect radiative effects in a climate model, Tellus B, 69, 1369342, https://doi.org/10.1080/16000889.2017.1369342, 2017.

Cohen, M. D., Stunder, B. J. B., Rolph, G. D., Draxler, R. R., Stein, A. F., and Ngan, F.: NOAA's HYSPLIT Atmospheric Transport and Dispersion Modeling System, B. Am. Meteorol. Soc., 96, 2059-2077, https://doi.org/10.1175/bams-d-14$00110.1,2015$.

Collier, S., Williams, L. R., Onasch, T. B., Cappa, C. D., Zhang, X., Russell, L. M., Chen, C.-L., Sanchez, K. J., Worsnop, D. R., and Zhang, Q.: Influence of Emissions and Aqueous Processing on Particles Containing Black Carbon in a Polluted Urban Environment: Insights From a Soot Particle-Aerosol Mass Spectrometer, J. Geophys. Res.-Atmos., 123, 6648-6666, https://doi.org/10.1002/2017jd027851, 2018.
Cui, X., Wang, X., Yang, L., Chen, B., Chen, J., Andersson, A., and Gustafsson, O.: Radiative absorption enhancement from coatings on black carbon aerosols, Sci. Total Environ., 551-552, 51-56, https://doi.org/10.1016/j.scitotenv.2016.02.026, 2016.

Ding, A. J., Huang, X., Nie, W., Sun, J. N., Kerminen, V. M., Petaja, T., Su, H., Cheng, Y. F., Yang, X. Q., Wang, M. H., Chi, X. G., Wang, J. P., Virkkula, A., Guo, W. D., Yuan, J., Wang, S. Y., Zhang, R. J., Wu, Y. F., Song, Y., Zhu, T., Zilitinkevich, S., Kulmala, M., and Fu, C. B.: Enhanced haze pollution by black carbon in megacities in China, Geophys. Res. Lett., 43, 2873-2879, https://doi.org/10.1002/2016g1067745, 2016.

Ding, S., Liu, D., Zhao, D., Hu, K., Tian, P., Zhou, W., Huang, M., Yang, Y., Wang, F., Sheng, J., Liu, Q., Kong, S., Cui, P., Huang, Y., He, H., Coe, H., and Ding, D.: Size-Related Physical Properties of Black Carbon in the Lower Atmosphere over Beijing and Europe, Environ. Sci. Technol., 53, 11112-11121, https://doi.org/10.1021/acs.est.9b03722, 2019.

Fan, H., Zhao, C., Yang, Y., Yang, X., and Wang, C.: Impact of emissions from a single urban source on air quality estimated from mobile observation and WRF-STILT model simulations, Air Qual. Atmos. Hlth., 14, 1313-1323, https://doi.org/10.1007/s11869-021-01023-9, 2021a.

Fan, H., Wang, Y., Zhao, C., Yang, Y., Yang, X., Sun, Y., and Jiang, S.: The Role of Primary Emission and Transboundary Transport in the Air Quality Changes During and After the COVID-19 Lockdown in China, Geophys. Res. Lett., 48, e2020GL091065, https://doi.org/10.1029/2020GL091065, $2021 b$.

Freney, E. J., Adachi, K., and Buseck, P. R.: Internally mixed atmospheric aerosol particles: Hygroscopic growth and light scattering, J. Geophys. Res., 115, D19210, https://doi.org/10.1029/2009jd013558, 2010.

Gao, R. S., Schwarz, J. P., Kelly, K. K., Fahey, D. W., Watts, L. A., Thompson, T. L., Spackman, J. R., Slowik, J. G., Cross, E. S., Han, J. H., Davidovits, P., Onasch, T. B., and Worsnop, D. R.: A Novel Method for Estimating LightScattering Properties of Soot Aerosols Using a Modified SingleParticle Soot Photometer, Aerosol Sci. Tech., 41, 125-135, https://doi.org/10.1080/02786820601118398, 2007.

Gong, X., Zhang, C., Chen, H., Nizkorodov, S. A., Chen, J., and Yang, X.: Size distribution and mixing state of black carbon particles during a heavy air pollution episode in Shanghai, Atmos. Chem. Phys., 16, 5399-5411, https://doi.org/10.5194/acp16-5399-2016, 2016.

He, C., Liou, K.-N., Takano, Y., Zhang, R., Levy Zamora, M., Yang, P., Li, Q., and Leung, L. R.: Variation of the radiative properties during black carbon aging: theoretical and experimental intercomparison, Atmos. Chem. Phys., 15, 11967-11980, https://doi.org/10.5194/acp-15-11967-2015, 2015.

Huang, X. F., Yu, J. Z., He, L. Y., and Hu, M.: Size distribution characteristics of elemental carbon emitted from Chinese vehicles: Results of a tunnel study and atmospheric implications, Environ. Sci. Technol., 40, 5355-5360, https://doi.org/10.1021/es0607281, 2006.

Huang, X.-F., Sun, T.-L., Zeng, L.-W., Yu, G.-H., and Luan, S.-J.: Black carbon aerosol characterization in a coastal city in South China using a single particle soot photometer, Atmos. Environ., 51, 21-28, https://doi.org/10.1016/j.atmosenv.2012.01.056, 2012. 
Ji, D., Li, L., Pang, B., Xue, P., Wang, L., Wu, Y., Zhang, H., and Wang, Y.: Characterization of black carbon in an urbanrural fringe area of Beijing, Environ. Pollut., 223, 524-534, https://doi.org/10.1016/j.envpol.2017.01.055, 2017.

Jimenez, J. L.: Ambient aerosol sampling using the Aerodyne Aerosol Mass Spectrometer, J. Geophys. Res., 108, 8452, https://doi.org/10.1029/2001jd001213, 2003.

Kondo, Y., Moteki, N., Oshima, N., Ohata, S., Koike, M., Shibano, Y., Takegawa, N., and Kita, K.: Effects of wet deposition on the abundance and size distribution of black carbon in East Asia, J. Geophys. Res.-Atmos., 121, 4691-4712, https://doi.org/10.1002/2015jd024479, 2016.

Kumar, B., Chakraborty, A., Tripathi, S. N., and Bhattu, D.: Highly time resolved chemical characterization of submicron organic aerosols at a polluted urban location, Environ. Sci.-Proc. Imp., 18, 1285-1296, https://doi.org/10.1039/c6em00392c, 2016.

Laborde, M., Mertes, P., Zieger, P., Dommen, J., Baltensperger, U., and Gysel, M.: Sensitivity of the Single Particle Soot Photometer to different black carbon types, Atmos. Meas. Tech., 5, 10311043, https://doi.org/10.5194/amt-5-1031-2012, 2012.

Laborde, M., Crippa, M., Tritscher, T., Jurányi, Z., Decarlo, P. F., Temime-Roussel, B., Marchand, N., Eckhardt, S., Stohl, A., Baltensperger, U., Prévôt, A. S. H., Weingartner, E., and Gysel, M.: Black carbon physical properties and mixing state in the European megacity Paris, Atmos. Chem. Phys., 13, 5831-5856, https://doi.org/10.5194/acp-13-5831-2013, 2013.

Lan, Z.-J., Huang, X.-F., Yu, K.-Y., Sun, T.-L., Zeng, L.W., and $\mathrm{Hu}, \mathrm{M} .:$ Light absorption of black carbon aerosol and its enhancement by mixing state in an urban atmosphere in South China, Atmos. Environ., 69, 118-123, https://doi.org/10.1016/j.atmosenv.2012.12.009, 2013.

Liu, D., Flynn, M., Gysel, M., Targino, A., Crawford, I., Bower, K., Choularton, T., Jurányi, Z., Steinbacher, M., Hüglin, C., Curtius, J., Kampus, M., Petzold, A., Weingartner, E., Baltensperger, U., and Coe, H.: Single particle characterization of black carbon aerosols at a tropospheric alpine site in Switzerland, Atmos. Chem. Phys., 10, 7389-7407, https://doi.org/10.5194/acp-10-7389-2010, 2010.

Liu, D., Allan, J., Whitehead, J., Young, D., Flynn, M., Coe, H., McFiggans, G., Fleming, Z. L., and Bandy, B.: Ambient black carbon particle hygroscopic properties controlled by mixing state and composition, Atmos. Chem. Phys., 13, 2015-2029, https://doi.org/10.5194/acp-13-2015-2013, 2013.

Liu, D., Joshi, R., Wang, J., Yu, C., Allan, J. D., Coe, H., Flynn, M. J., Xie, C., Lee, J., Squires, F., Kotthaus, S., Grimmond, S., Ge, X., Sun, Y., and Fu, P.: Contrasting physical properties of black carbon in urban Beijing between winter and summer, Atmos. Chem. Phys., 19, 6749-6769, https://doi.org/10.5194/acp-19-6749-2019, 2019.

Liu, D. T., Whitehead, J., Alfarra, M. R., Reyes-Villegas, E., Spracklen, D. V., Reddington, C. L., Kong, S. F., Williams, P. I., Ting, Y. C., Haslett, S., Taylor, J. W., Flynn, M. J., Morgan, W. T., McFiggans, G., Coe, H., and Allan, J. D.: Black-carbon absorption enhancement in the atmosphere determined by particle mixing state, Nat. Geosci., 10, 184-188, https://doi.org/10.1038/ngeo2901, 2017.

Liu, H., Pan, X., Wu, Y., Ji, D., Tian, Y., Chen, X., and Wang, Z.: Size-resolved mixing state and optical properties of black car- bon at an urban site in Beijing, Sci. Total Environ., 749, 141523 , https://doi.org/10.1016/j.scitotenv.2020.141523, 2020a.

Liu, H., Pan, X., Liu, D., Liu, X., Chen, X., Tian, Y., Sun, Y., Fu, P., and Wang, Z.: Mixing characteristics of refractory black carbon aerosols at an urban site in Beijing, Atmos. Chem. Phys., 20, 5771-5785, https://doi.org/10.5194/acp-20-5771-2020, 2020 b.

Liu, S., Aiken, A. C., Gorkowski, K., Dubey, M. K., Cappa, C. D., Williams, L. R., Herndon, S. C., Massoli, P., Fortner, E. C., Chhabra, P. S., Brooks, W. A., Onasch, T. B., Jayne, J. T., Worsnop, D. R., China, S., Sharma, N., Mazzoleni, C., Xu, L., Ng, N. L., Liu, D., Allan, J. D., Lee, J. D., Fleming, Z. L., Mohr, C., Zotter, P., Szidat, S., and Prevot, A. S. H.: Enhanced light absorption by mixed source black and brown carbon particles in UK winter, Nat. Commun., 6, 8435, https://doi.org/10.1038/ncomms9435, 2015.

Moffet, R. C. and Prather, K. A.: In-situ measurements of the mixing state and optical properties of soot with implications for radiative forcing estimates, P. Natl. Acad. Sci. USA, 106, 11872 11877, https://doi.org/10.1073/pnas.0900040106, 2009.

Moteki, N. and Kondo, Y.: Effects of Mixing State on Black Carbon Measurements by Laser-Induced Incandescence, Aerosol Sci. Tech., 41, 398-417, https://doi.org/10.1080/02786820701199728, 2007.

Moteki, N., Kondo, Y., Oshima, N., Takegawa, N., Koike, M., Kita, K., Matsui, H., and Kajino, M.: Size dependence of wet removal of black carbon aerosols during transport from the boundary layer to the free troposphere, Geophys. Res. Lett., 39, L13802, https://doi.org/10.1029/2012gl052034, 2012.

Oshima, N., Koike, M., Zhang, Y., Kondo, Y., Moteki, N., Takegawa, N., and Miyazaki, Y.: Aging of black carbon in outflow from anthropogenic sources using a mixing state resolved model: Model development and evaluation, J. Geophys. Res., 114, D06210, https://doi.org/10.1029/2008jd010680, 2009.

Pan, X., Kanaya, Y., Taketani, F., Miyakawa, T., Inomata, S., Komazaki, Y., Tanimoto, H., Wang, Z., Uno, I., and Wang, Z.: Emission characteristics of refractory black carbon aerosols from fresh biomass burning: a perspective from laboratory experiments, Atmos. Chem. Phys., 17, 13001-13016, https://doi.org/10.5194/acp-17-13001-2017, 2017.

Saathoff, H., Naumann, K. H., Schnaiter, M., Schöck, W., Möhler, O., Schurath, U., Weingartner, E., Gysel, M., and Baltensperger, U.: Coating of soot and $\left(\mathrm{NH}_{4}\right) 2 \mathrm{SO} 4$ particles by ozonolysis products of $\alpha$-pinene, J. Aerosol Sci., 34, 1297-1321, https://doi.org/10.1016/s0021-8502(03)00364-1, 2003.

Sarangi, B., Ramachandran, S., Rajesh, T. A., and Dhaker, V. K.: Black carbon linked aerosol hygroscopic growth: Size and mixing state are crucial, Atmos. Environ., 200, 110-118, https://doi.org/10.1016/j.atmosenv.2018.12.001, 2019.

Schnaiter, M.: Absorption amplification of black carbon internally mixed with secondary organic aerosol, J. Geophys. Res., 110, D19204, https://doi.org/10.1029/2005jd006046, 2005.

Schwarz, J. P., Gao, R. S., Fahey, D. W., Thomson, D. S., Watts, L. A., Wilson, J. C., Reeves, J. M., Darbeheshti, M., Baumgardner, D. G., Kok, G. L., Chung, S. H., Schulz, M., Hendricks, J., Lauer, A., Karcher, B., Slowik, J. G., Rosenlof, K. H., Thompson, T. L., Langford, A. O., Loewenstein, M., and Aikin, K. C.: Single-particle measurements of midlatitude black carbon and light-scattering aerosols from the boundary layer to 
the lower stratosphere, J. Geophys. Res.-Atmos., 111, D16207, https://doi.org/10.1029/2006jd007076, 2006a.

Schwarz, J. P., Gao, R. S., Fahey, D. W., Thomson, D. S., Watts, L. A., Wilson, J. C., Reeves, J. M., Darbeheshti, M., Baumgardner, D. G., Kok, G. L., Chung, S. H., Schulz, M., Hendricks, J., Lauer, A., Karcher, B., Slowik, J. G., Rosenlof, K. H., Thompson, T. L., Langford, A. O., Loewenstein, M., and Aikin, K. C.: Single-particle measurements of midlatitude black carbon and light-scattering aerosols from the boundary layer to the lower stratosphere, J. Geophys. Res.-Atmos., 111, 15, https://doi.org/10.1029/2006jd007076, 2006b.

Schwarz, J. P., Gao, R. S., Spackman, J. R., Watts, L. A., Thomson, D. S., Fahey, D. W., Ryerson, T. B., Peischl, J., Holloway, J. S., Trainer, M., Frost, G. J., Baynard, T., Lack, D. A., de Gouw, J. A., Warneke, C., and Del Negro, L. A.: Measurement of the mixing state, mass, and optical size of individual black carbon particles in urban and biomass burning emissions, Geophys. Res. Lett., 35, L13810, https://doi.org/10.1029/2008g1033968, 2008.

Simpson, A. J. and McGee, O. S.: Analysis of the Fumigation Effect on Pollutants over Pietermaritzburg, S. Afr. Geogr. J., 78, 41-46, https://doi.org/10.1080/03736245.1996.9713605, 2012.

Stephens, M., Turner, N., and Sandberg, J.: Particle identification by laser-induced incandescence in a solid-state laser cavity, Appl. Optics, 42, 3726-3736, https://doi.org/10.1364/ao.42.003726, 2003.

$\mathrm{Su}$, J., Zhao, P., and Chen, Y.: Characteristics of Number Concentration Size Distributions of Aerosols Under Different Weather Processes in Beijing, Environm. Sci., 37, 1208-1218, 2016.

Su, L., Yuan, Z., Fung, J. C., and Lau, A. K.: A comparison of HYSPLIT backward trajectories generated from two GDAS datasets, Sci. Total Environ., 506-507, 527-537, https://doi.org/10.1016/j.scitotenv.2014.11.072, 2015.

Sun, J., Xie, C., Xu, W., Chen, C., Ma, N., Xu, W., Lei, L., Li, Z., He, Y., Qiu, Y., Wang, Q., Pan, X., Su, H., Cheng, Y., Wu, C., Fu, P., Wang, Z., and Sun, Y.: Light absorption of black carbon and brown carbon in winter in North China Plain: comparisons between urban and rural sites, Sci. Total Environ., 770, 144821, https://doi.org/10.1016/j.scitotenv.2020.144821, 2021.

Sun, Y., Zhao, C., Su, Y., Ma, Z., Li, J., Letu, H., Yang, Y., and Fan, H.: Distinct Impacts of Light and Heavy Precipitation on $\mathrm{PM}_{2.5}$ Mass Concentration in Beijing, Earth Space Science, 6, 1915-1925, https://doi.org/10.1029/2019ea000717, 2019.

Talukdar, S., Venkat Ratnam, M., Ravikiran, V., and Chakraborty, R.: Influence of Black Carbon Aerosol on the Atmospheric Instability, J. Geophys. Res.-Atmos., 124, 5539-5554, https://doi.org/10.1029/2018jd029611, 2019.

Taylor, J. W., Allan, J. D., Allen, G., Coe, H., Williams, P. I., Flynn, M. J., Le Breton, M., Muller, J. B. A., Percival, C. J., Oram, D., Forster, G., Lee, J. D., Rickard, A. R., Parrington, M., and Palmer, P. I.: Size-dependent wet removal of black carbon in Canadian biomass burning plumes, Atmos. Chem. Phys., 14, 13755-13771, https://doi.org/10.5194/acp-14-137552014, 2014.

Taylor, J. W., Allan, J. D., Liu, D., Flynn, M., Weber, R., Zhang, X., Lefer, B. L., Grossberg, N., Flynn, J., and Coe, H.: Assessment of the sensitivity of core / shell parameters derived using the singleparticle soot photometer to density and refractive index, Atmos. Meas. Tech., 8, 1701-1718, https://doi.org/10.5194/amt-8-17012015, 2015.
Twomey, S.: Pollution and planetary albedo, Atmos. Environ., 8, 1251-1256, https://doi.org/10.1016/0004-6981(74)90004-3, 1974.

Wang, Q., Huang, R. J., Cao, J., Han, Y., Wang, G., Li, G., Wang, Y., Dai, W., Zhang, R., and Zhou, Y.: Mixing State of Black Carbon Aerosol in a Heavily Polluted Urban Area of China: Implications for Light Absorption Enhancement, Aerosol Sci. Tech., 48, 689697, https://doi.org/10.1080/02786826.2014.917758, 2014.

Wang, Q., Cao, J., Han, Y., Tian, J., Zhu, C., Zhang, Y., Zhang, N., Shen, Z., Ni, H., Zhao, S., and Wu, J.: Sources and physicochemical characteristics of black carbon aerosol from the southeastern Tibetan Plateau: internal mixing enhances light absorption, Atmos. Chem. Phys., 18, 4639-4656, https://doi.org/10.5194/acp18-4639-2018, 2018.

Wu, Y., Zhang, R., Tian, P., Tao, J., Hsu, S. C., Yan, P., Wang, Q., Cao, J., Zhang, X., and Xia, X.: Effect of ambient humidity on the light absorption amplification of black carbon in Beijing during January 2013, Atmos. Environ., 124, 217-223, https://doi.org/10.1016/j.atmosenv.2015.04.041, 2016.

Wu, Y., Xia, Y., Zhou, C., Tian, P., Tao, J., Huang, R. J., Liu, D., Wang, X., Xia, X., Han, Z., and Zhang, R.: Effect of source variation on the size and mixing state of black carbon aerosol in urban Beijing from 2013 to 2019: Implication on light absorption, Environ. Pollut., 270, 116089, https://doi.org/10.1016/j.envpol.2020.116089, 2021.

Xie, C., He, Y., Lei, L., Zhou, W., Liu, J., Wang, Q., Xu, W., Qiu, Y., Zhao, J., Sun, J., Li, L., Li, M., Zhou, Z., Fu, P., Wang, Z., and Sun, Y.: Contrasting mixing state of black carbon-containing particles in summer and winter in Beijing, Environ. Pollut., 263, 114455, https://doi.org/10.1016/j.envpol.2020.114455, 2020.

Xie, C. H., Xu, W. Q., Wan, J. F., Liu, D. T., Ge, X. L., Zhang, Q., Wang, Q., Du, W., Zhao, J., Zhou, W., Li, J., Fu, P. Q., Wang, Z. F., Worsnop, D. L., and Sun, Y. L.: Light absorption enhancement of black carbon in urban Beijing in summer, Atmos. Environ., 213, 499-504, https://doi.org/10.1016/j.atmosenv.2019.06.041, 2019.

Xu, X., Zhao, W., Qian, X., Wang, S., Fang, B., Zhang, Q., Zhang, W., Venables, D. S., Chen, W., Huang, Y., Deng, X., Wu, B., Lin, X., Zhao, S., and Tong, Y.: The influence of photochemical aging on light absorption of atmospheric black carbon and aerosol single-scattering albedo, Atmos. Chem. Phys., 18, 16829-16844, https://doi.org/10.5194/acp-18-16829-2018, 2018.

Yang, X., Zhao, C., Zhou, L., Wang, Y., and Liu, X.: Distinct impact of different types of aerosols on surface solar radiation in China, J. Geophys. Res.-Atmos., 121, 6459-6471, https://doi.org/10.1002/2016jd024938, 2016.

Yu, C., Liu, D., Broda, K., Joshi, R., Olfert, J., Sun, Y., Fu, P., Coe, H., and Allan, J. D.: Characterising mass-resolved mixing state of black carbon in Beijing using a morphology-independent measurement method, Atmos. Chem. Phys., 20, 3645-3661, https://doi.org/10.5194/acp-20-3645-2020, 2020.

Zhang, X., Kim, H., Parworth, C. L., Young, D. E., Zhang, Q., Metcalf, A. R., and Cappa, C. D.: Optical Properties of Wintertime Aerosols from Residential Wood Burning in Fresno, CA: Results from DISCOVER-AQ 2013, Environ. Sci. Technol., 50, 16811690, https://doi.org/10.1021/acs.est.5b04134, 2016.

Zhang, Y., Zhang, Q., Cheng, Y., Su, H., Li, H., Li, M., Zhang, X., Ding, A., and He, K.: Amplification of light absorption of black 
carbon associated with air pollution, Atmos. Chem. Phys., 18, 9879-9896, https://doi.org/10.5194/acp-18-9879-2018, 2018a.

Zhang, Y., Favez, O., Canonaco, F., Liu, D., Močnik, G., Amodeo, T., Sciare, J., Prévôt, A. S. H., Gros, V., and Albinet, A.: Evidence of major secondary organic aerosol contribution to lensing effect black carbon absorption enhancement, npj Climate and Atmospheric Science, 1, 47, https://doi.org/10.1038/s41612018-0056-2, 2018b.

Zhao, D., Liu, D., Yu, C., Tian, P., Hu, D., Zhou, W., Ding, S., Hu, K., Sun, Z., Huang, M., Huang, Y., Yang, Y., Wang, F., Sheng, J., Liu, Q., Kong, S., Li, X., He, H., and Ding, D.: Vertical evolution of black carbon characteristics and heating rate during a haze event in Beijing winter, Sci. Total Environ., 709, 136251, https://doi.org/10.1016/j.scitotenv.2019.136251, 2020.
Zhao, G., Shen, C., and Zhao, C.: Technical note: Mismeasurement of the core-shell structure of black carbon-containing ambient aerosols by SP2 measurements, Atmos. Environ., 243, 117885, https://doi.org/10.1016/j.atmosenv.2020.117885, 2020.

Zhao, X., Sun, Y., Zhao, C., and Jiang, H.: Impact of Precipitation with Different Intensity on $\mathrm{PM}_{2.5}$ over Typical Regions of China, Atmosphere, 11, 906, https://doi.org/10.3390/atmos11090906, 2020 . 